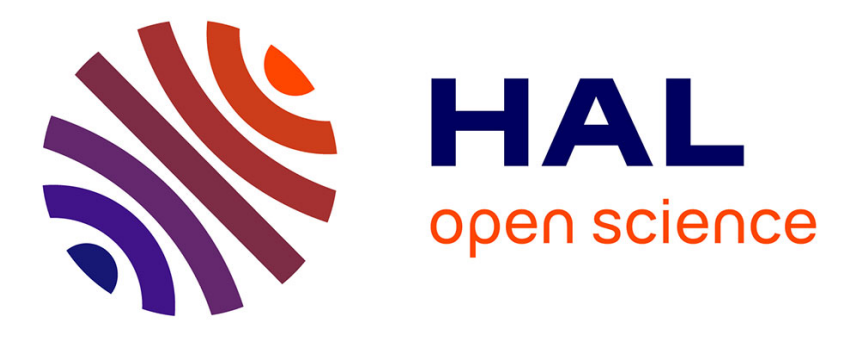

\title{
Laboratory simulation of debris flows over sand dunes: Insights into gully-formation (Mars)
}

Gwenaël Jouannic, Julien Gargani, Susan J. Conway, F. Costard, Matthew R. Balme, Manish R. Patel, Marion Massé, Chiara Marmo, Vincent Jomelli, Gian G. Ori

\section{To cite this version:}

Gwenaël Jouannic, Julien Gargani, Susan J. Conway, F. Costard, Matthew R. Balme, et al.. Laboratory simulation of debris flows over sand dunes: Insights into gully-formation (Mars). Geomorphology, 2015, 231, pp.101 - 115. 10.1016/j.geomorph.2014.12.007 . hal-01483501

\section{HAL Id: hal-01483501 https://hal.science/hal-01483501}

Submitted on 8 Jan 2021

HAL is a multi-disciplinary open access archive for the deposit and dissemination of scientific research documents, whether they are published or not. The documents may come from teaching and research institutions in France or abroad, or from public or private research centers.
L'archive ouverte pluridisciplinaire HAL, est destinée au dépôt et à la diffusion de documents scientifiques de niveau recherche, publiés ou non, émanant des établissements d'enseignement et de recherche français ou étrangers, des laboratoires publics ou privés. 
4 Gwenaël Jouannic ${ }^{1,2^{*}}$, Julien Gargani ${ }^{1}$, Susan J. Conway ${ }^{3}$, François Costard ${ }^{1}$, Matthew R. 5 Balme $^{3,4}$, Manish R. Patel ${ }^{3}$, Marion Massé ${ }^{5}$, Chiara Marmo ${ }^{1}$, Vincent Jomelli ${ }^{6}$, Gian G. Ori ${ }^{7}$

6 (1) GEOPS, Université Paris-Sud, CNRS/INSU UMR 8148, Bât. 509, 91405 Orsay, France.

(2) Cerema, Direction Territoriale Est, Laboratoire de Nancy, 54510 Tomblaine, France.

(3) Department of Physical Sciences, CEPSAR, Open University, Walton Hall, Milton Keynes MK7 6AA, UK.

(4) Planetary Science Institute, Suite 106, 1700 East Fort Lowell Road, Tucson, AZ 85719, USA.

(5) Laboratoire de Planétologie et Géodynamique, CNRS/INSU UMR 6112, Université de Nantes, 2 chemin de la Houssinière, BP 92205, 44322 Nantes Cedex 3, France..

(6) University of Pantheon Sorbonne - Paris I, CNRS, Lab Geog, Meudon, France.

(7) International Research School of Planetary Sciences, Università “G. d'Annunzio", Viale Pindaro 42, 65127 Pescara, Italy.

$18 *$ Corresponding author now at: Cerema, Direction Territoriale Est, Laboratoire Régional de 19 Nancy, 54510 Tomblaine, France. Tel.: + 33383184119.

21 E-mail addresses : gwenael.jouannic@cerema.fr (G. Jouannic), julien.gargani@u-psud.fr (J.

22 Gargani), Susan.Conway@open.ac.uk (S.J. Conway), francois.costard@u-psud.fr (F. Costard), 
24

\section{Abstract}

matt.balme@open.ac.uk

(M.R. Balme), manish.patel@ open.ac.uk chiara.marmo@u-psud.fr

(C. Marmo) ggori@irsps.unich.it (G.G. Ori)
(M.R. Patel),

(V. Jomelli),

Gully morphology (often summarized as comprising an alcove, channel and debris apron) is one of the key elements used to support the argument for liquid water in the recent past on Mars. Nevertheless, the processes that create different gully morphologies, both on Mars and on Earth, are not fully understood. One of the puzzling morphologic attributes of martian dune gullies is their apparent lack of an apron, or terminal deposit, which has caused debate about their formation process. Several physical processes could explain the formation of these gullies (e.g. runoff, debris flows, granular flows, sliding blocks falling downslope). In this work, we focus on the role of liquid in the substrate as well as in the flow and choose to experimentally test the plausibility of this hypothesis. We performed a series of analog experiments to investigate the formation of gullies on sand dune-like substrates. We used controlled flows of water over an inclined sand-box to produce gully-like forms. Ice-rich sedimentary substrates were used, including substrates that included a thin liquid water-saturated thawed layer (an 'active layer') above the ice-saturated zone to give an analogue for a 'periglacial' environment. We quantitatively demonstrate that debris flow processes in 'periglacial' experiments are conducive to the formation of narrow and long channels with small terminal deposits with perched channels. By re-analysis of martian elevation data for dune-gullies on Mars, we have found good evidence that such terminal deposits could exist. Our experiments revealed that increased water content in the thawed layer above the frozen bed increases flow-length due to the subsequent reduction in 
46 infiltration capacity. Water is incorporated into the flow by erosion of the wet thawed layer (sand

47 plus water) and by drainage of the thawed layer. Using a Mars environment simulation chamber,

48 we found that atmospheric pressure conditions seem to have a limited influence on the

49 morphology of the flows. Our experimental investigation allowed us to reproduce terrestrial

50 debris flow and Martian gully morphologies, suggesting that a substrate that is resistant to

51 infiltration could be present beneath the dune gullies on Mars. We suggest that, like in our

52 laboratory experiments, the presence of ice at shallow depth is a possible explanation for the

53 formation of these morphologies and that a wet thawed layer is a possible explanation for the

54 long flow-length.

55

56

57

58

59 Keywords: Periglacial, debris flow, water, active layer, pore pressure, perched channel 


\section{Introduction}

61

62 Diverse gully morphologies occur on Mars and on Earth (Fig. 1), but the processes and climatic 63 conditions that form the different morphologies remain poorly understood. On Mars, km-scale 64 landforms with distinctive 'alcove-channel-debris apron' morphology are generically referred to 65 as "gullies" (e.g., Malin and Edgett, 2001; Costard et al., 2002). Although a wide range of 66 landforms on Mars fit this description, in general there are three main 'types' of martian gully: (i)

67 'classic' gullies which have well defined alcoves, channels and aprons, and which form in 68 bedrock or scree-like mass wasting deposits, (ii) 'pasted-on material' gullies (Fig 1b), which have 69 large, elongate alcoves, small channels and very small debris apron, and which form in fine70 grained mantling deposits that appear to be 'pasted-on' to valley walls and impact crater inner71 rims (e.g. Christensen, 2003; Aston et al., 2011), and (iii) 'dune' gullies (Fig 1c) which have 72 long, well defined channels, very small alcoves and (apparently) small to non-existent debris 73 aprons, and which form on sand-covered slopes (most often, the slip faces of sand dunes). Here, 74 we concentrate on martian 'dune' gullies of the type illustrated in Figure. 1f.

75 The discovery of martian gullies (Malin and Edgett, 2000) triggered numerous debates 76 and interpretations. Several hypotheses have been suggested for the formation of gullies: (i) 77 runoff and debris flows with liquid water from groundwater aquifers (Malin and Edgett, 2000;

78 Heldmann and Mellon 2004), (ii) snow-melt (Christensen, 2003; Dickson et al., 2007; Williams 79 et al., 2009; Hauber et al, 2011), (iii) liquid $\mathrm{CO}_{2}$ breakout (Musselwhite, 2001), (iv) melting of 80 near-surface ground ice (<1 m meter) at high obliquity (Costard et al., 2002; Mangold et al., 81 2003; Balme et al, 2006), (v) geothermally-heated aquifers (Gaidos, 2001; Hartmann, 2001), (vi) 82 the presence of brines may have played a role (Knauth et al., 2000; Knauth and Burt, 2003; 
83 Chevrier et al., 2009), (vii) processes involving $\mathrm{CO}_{2}$ frost (Hoffman, 2002; Ishii and Sasaki, 84 2004; Cedillo-Flores et al., 2011), or $\mathrm{CO}_{2}$ blocks falling down slope (Diniega et al., 2013). The availability of High Resolution Imaging Science Experiment (HiRISE) images (McEwen et al., 2007) and HiRISE Digital Terrain Models (DTM) has allowed the morphology of the gullies to

87 be characterized in more detail than ever before (e.g., Mangold et al., 2003; Pelletier et al., 2008; Kolb et al., 2010; Mangold et al., 2010; Lanza et al., 2010; Conway et al. 2011a).

On Earth, there are many examples of gullies that are similar in morphology to 'classic' martian gullies, especially in periglacial environments (Fig. 1; Jomelli and Francou, 2000;

91 Costard et al., 2002; Hauber et al., 2011; Sattler et al., 2011), but only a few landforms resembling martian dune gullies have been observed (e.g. Fig. 1c). These include gullies on dunes that are in (i) arid environments that formed by granular flow process (Cunene Sand Sea in Namibia and White Sand in New Mexico; Horgan and Bell, 2012) or (ii) cold-climate regions that formed by sand-water flows (Hugenholtz et al. 2007; Hooper and Dinwiddie, 2014).

Even if several physical processes could explain the formation of gullies, we have chosen to focus our study on the role of the liquid contained into the substrate to test the role of this mechanism and the feasibility of this process. Several studies (Costard et al., 2002; Mangold et al., 2003) have suggested that the formation of 'classic' martian gully morphologies involves flows with a significant proportion of liquid, as indicated by the presence of sinuosity and tributary/distributary systems. However, the apparent lack of well-developed terminal deposits on dune gullies and their long runout distances $(\sim 2 \mathrm{~km})$ over gentle slopes $\left(8-10^{\circ}\right)$ are hard to 103 reconcile with any given formation process (Jouannic et al., 2012a). Dry sand experiments could 104 trigger the formation of scars, levees and channels but only on steep slopes of $30^{\circ}$ (McDonald and Anderseon, 1996) and their morphologies are very different (Sutton et al., 2013 a and b) from 
107 For example, the gullies on Matara Crater dunes and the Russell crater megadune have features characteristic of liquid water flow (sinuosity, tributaries, distributaries), but their lack of well109 developed terminal deposits is inconsistent with water flow and has led people to cite dry processes, such as sliding $\mathrm{CO}_{2}$ blocks (e.g., Diniega et al., 2013). The presence of lateral levees

111 on either side of these gullies has led some authors to suggest debris flow as a viable option 112 (Mangold et al., 2003; Reiss and Jaumann, 2003; Jouannic et al, 2012a) and this could offer a 113 solution to these apparently conflicting observations.

114 Debris flow (a non-newtonian flow process comprising a sediment-water mix, Iverson, 115 1997) is a common process attributed to gully formation on both Earth and Mars (Coussot and 116 Meunier, 1996; Mangold et al., 2003; Jouannic et al., 2012a) and provides a plausible candidate 117 for the formation of martian dune gullies, in that it can be both erosive and depositional, forms 118 sinuous, leveed channels, and can occur on relatively shallow slopes. Many variables can 119 influence the morphology of debris flows (grain size, discharge, slope, soil moisture, pre-existing 120 topography) and their respective influences are difficult to disentangle in the field (Coleman et 121 al., 2008). Of particular interest as an analogue for martian dune-gullies are observations of 122 'perched' channels in the terminal deposits of debris flows on Earth (Coe et al., 2002; Larsson, 123 1982). These are erosional channels that form within deposited sediment, but are topographically 124 above the surrounding, pre-flow surface. Hence, they are part of the depositional system of the 125 debris flow, but in plan-view they could be easily mistaken for part of the erosional system. If 126 perched channels are found to occur in martian dune gullies, this could explain why previous 127 work has reported only limited deposits for these gullies. Examples of a perched channels from 128 La Clarée valley (French Alps) is shown in Figure 2 and for fresh debris flows located near 
129 Ísafjörður in NW Iceland (Fig. 3) in the vicinity of flows studied by Conway et al. (2010). A V130 shaped incision, or channel, is visible in the erosional upstream zone where the flow has high 131 energy (Fig. 2a). A U-shaped channel (Fig. 2b) is present on gentler slopes in the downstream 132 zone and in this part of the debris flow no erosion occurred, but simply deposition of lateral 133 levees. In the terminal part of the flow, a perched channel is present (Figs. 2b, 2c and 3). Field 134 observations of the foot of trees located inside the channel of the gully covered by the sediments 135 deposited under the channel confirmed that the bottom of the channel is at higher elevation than 136 the surrounding topography (Fig. 2c). Hence, for debris flows, the presence of a channel is not a 137 solely sufficient indicator of erosion. A channel can still be present even though there is no net 138 erosion, or any erosion at all.

139 Perched channels of this kind within debris flows tend to occur in periglacial 140 environments on Earth (Larsson 1982), suggesting that the presence of ground ice and/or a 141 thawed layer (a seasonally active thawed layer above permanently frozen ground) is important for 142 generating these morphologies. We aim to explore how this idea can be applied to dune gullies 143 on Mars using a combination of remote sensing and laboratory simulation.

144 Preliminary laboratory simulations of this kind have been performed, including cold room 145 experiments (Védie et al., 2008) which showed the qualitative effect of a melted surface layer 146 (simulating the thawed layer) on the formation of gullies in sand dune slip faces. Nevertheless, 147 the influence of the liquid water content of the thawed layer on the gully morphology has never 148 been investigated. Only one Mars-relevant experiment has been performed to date to test the 149 effect of atmospheric pressure on erosional capacity and runout distance of the flows (Conway et 150 al., 2011b), but the experiments were not conducted considering an ice-rich sediment substrate. 
In this study we explore the formation mechanisms of gullies observed on large sand 152 dunes on Mars. Using analogue experiments we have investigated (i) the influence of 153 atmospheric pressure (martian/terrestrial pressure) on gully morphology; (ii) the role of the liquid 154 water content of a thawed layer above a frozen substrate on gully morphology; (iii) the processes 155 leading to perched channel morphologies; and (iv) the influence of desiccation/sublimation 156 processes on the degradation of the gully morphology. Furthermore, using remote sensing and 157 terrain analysis methods we have reexamined dune gullies on Mars and find that several gullies 158 contain 'perched channels' in the downstream section. Such features have not been described on 159 martian dune gullies before.

162 2.1 Martian orbital data

163 In order to investigate whether perched channels are present in dune gullies on Mars, we studied 164 the Russell Crater megadune $\left(54.5^{\circ} \mathrm{S} ; 12.7^{\circ} \mathrm{E}\right)$ and a barchan dune inside Kaiser Crater $\left(46.7^{\circ} \mathrm{S}\right.$; $16520.1^{\circ} \mathrm{E}$ ), because they both possess gullies on the dune slip faces. High Resolution Imaging 166 Science Experiment (HiRISE) images (McEwen et al., 2007) have been used to describe gully 167 morphology. The resolution of HiRISE images $(25-100 \mathrm{~cm} /$ pix $)$ allows detailed morphological 168 observations to be made. A Transverse Mercator projection was used for all images, with the 169 centre longitude the same as the image center. We used a HiRISE Digital Terrain Model (DTM), 170 produced using stereo photogrammetry methods developed by the USGS (Kirk et al., 2008), to 171 analyze the topography of the Russell Crater and Kaiser Crater dunes and their gullies. For a full 172 description of the HiRISE DTM creation procedure, see Jouannic et al. (2012a). To study the 
173 Kaiser dune we used a publically available HiRISE DTM 174 (http://hirise.lpl.arizona.edu/dtm/dtm.php?ID=PSP_006899_1330).

175 The HiRISE DTMs are of sufficient quality and resolution to allow channels only a few 176 metres wide to be resolved. The high resolution DTM of the Russell crater dune reveals fine177 scale structures of the gullies, including lateral levees. Concerning the uncertainty of the HiRISE 178 DTM, previous studies have estimated their vertical precision to be better than $25 \mathrm{~cm}$ (Pelletier et 179 al., 2008; Mattson et al., 2011; Jouannic et al., 2012a). In this study, we considered conservative 180 vertical uncertainties of $0.25 \mathrm{~m}$ in the DTMs containing the gullies of the Russell Crater 181 megadune and the Kaiser Crater barchan.

$183 \quad 2.2$ Terrestrial orbital data

184 Aerial images and airborne laser altimeter (LiDAR) data were acquired on 12 August 2013 by the 185 UK's Natural Environment Research Council's Airborne Research and Survey Facility (NERC 186 ARSF) near Ísafjörður in NW Iceland (Fig.3). The LiDAR instrument used was a Leica ALS50-II 187 and the point density ranged between 1 and 4 hits $/ \mathrm{m}^{2}$ (mean $\sim 2.9$ ). The point data were post188 processed by the ARSF data analysis node (ARSF-DAN) and estimated vertical errors (taking 189 into account between-strip errors) are $\sim 6 \mathrm{~cm}$. The data were gridded at $1 \mathrm{~m} / \mathrm{pix}$ using lasTools. 190 The survey included small debris flows over talus slopes located in the vicinity of flows studied 191 by Conway et al. (2010). Neither of these flows were visible in the aerial images or have a 192 topographic signature in the LIDAR data acquired in 2007 by Conway et al. (2010), hence 193 occurred between the two survey dates. 194

$195 \quad 2.3$ Laboratory simulations 
196 We performed a set of debris flow experiments under martian atmospheric pressure ( 6 mbar) in 197 the Mars Chamber (Fig. 4a) at the Open University (Milton Keynes, UK) and under terrestrial 198 atmospheric pressure in a cold room (Fig. 4b) at the IDES laboratory (Orsay, France). One aim of 199 this study was to characterize the influence of atmospheric pressure on gully morphology. The 200 Mars Chamber enabled us to perform these experiments under the low pressure conditions as 201 found at the surface of Mars, while the terrestrial cold room allowed us to perform reference 202 experiments with an accurate control of atmospheric and frozen bed temperature, as well as 203 control of water content inside the 'thawed layer'.

204 In both cases, the experiments were performed using a fine sand (200-250 $\mu \mathrm{m})$ substrate, 205 which had been saturated in water and completely frozen. Before some of the experiments were 206 performed, the uppermost few millimeters $(2-6 \mathrm{~mm})$ were allowed to defrost to form a thin 207 'thawed layer'. This creates a sandy, frozen bed with a moist surface layer, which can be inclined 208 at various angles to produce an analogue for the slip face of a martian or terrestrial dune.

209 The experiments were performed by depositing a measured amount of water at a 210 controlled flow rate from a point source at the top of the inclined substrate. This creates a small 211 debris flow which propagates downslope and terminates shortly after the flow of water at the top 212 of the substrate is halted. The result of each experiment is a well-defined debris-flow landform 213 that can include an eroded channel, levees and a blunt lobe-like debris apron. The final 214 morphology generated by each run was precisely measured using a laser scanner. During the 215 experimental program the following parameters were varied to explore the parameter space: 216 discharge, slope-angle, water content of the thawed layer and thickness of the thawed layer.

217 The experiment allowed us to quantify the erosion and the deposition volumes, as detailed 218 in Section 2.3.3. The water content of the thawed layer $C_{\mathrm{w}}$ was estimated measuring the ratio 
219 between weights of wet sediment $W_{\text {wet sediment }}$ and dry sediments $W_{\text {dry sediment }}$. More precisely, the

220 water content has obtained using the equation: $C_{\mathrm{w}}=\left(W_{\text {wet sediment }}-W_{\text {dry sediment }}\right) / W_{\text {dry sediment. }}$

$222 \quad$ 2.3.1 Terrestrial cold room (Univ. Paris-Sud facility) experiments and procedures

223 To simulate a periglacial environment, a cold room large enough to accommodate an

224 experimental slope was used (Fig. 4b). The test bed was a $2.5 \mathrm{~m}$ long, $0.5 \mathrm{~m}$ wide and $0.2 \mathrm{~m}$ deep

225 rectangular tray located inside the cold room (Fig. 4b). A $\sim 10 \mathrm{~cm}$ deep frozen layer composed of

226 sand material saturated in water was placed in this tray to form the sediment substrate. Once

227 completely frozen (after one night at $-10^{\circ} \mathrm{C}$ ), the cold room cooling was switched off and, where

228 appropriate for the experiment to be performed, a defrosted layer allowed to form. The surface

229 temperature was monitored using thermocouples: the temperature of the thawed layer was $\sim 0^{\circ} \mathrm{C}$

230 during the experiments. Once the desired depth of melting had been achieved (after $\sim 1-3 \mathrm{~h}$ ),

231 water was introduced from an external reservoir for a set duration. The temperature of the thawed

232 layer was monitored throughout. Water was introduced from a pipe at the upper edge of the test

233 bed and allowed to flow down and across the sediment substrate. Each experiment lasted between

$234 \sim 11 \mathrm{~s}$ and $\sim 13 \mathrm{~s}$ and a total of $\sim 60 \pm 10 \mathrm{ml}$ of water was used for each experiment (Table 1). Two

235 experimental runs were conducted under the same initial conditions in order to check

236 experimental repeatability. The experiments were monitored using a video device and

237 photographic documentation was performed for each experimental run. A peristaltic pump

238 allowed external control over the release rate of water at ambient temperature $\left(\sim 15^{\circ} \mathrm{C}\right)$. Due to

239 the very short duration of the flow, no significant melting of the frozen bed was triggered by

240 thermal erosion. 
242 different points on the surface of the frozen layer. The water content of the thawed layer was

243 calculated after each experiment by measuring the difference of the weight of a thawed layer

244 sample with water and then without water (after the complete drying of the sample) using a

245 digital balance (accuracy $\sim 0.1 \mathrm{~g}$ ). In situ laser scanning was performed before and after each

246 experiment to generate a full elevation model of the sediment surface (vertical precision of

$247 \sim 0.1 \mathrm{~mm}$ ) and to measure the before/after changes. The propagation velocity of the flow was

248 calculated from the video device data. The pressure in the cold chamber was at the terrestrial

249 atmospheric pressure of 1 bar.

250 In order to investigate how the morphology changed as a result of desiccation, the cold

251 room was switched on $\left(>24\right.$ hours at $\left.\mathrm{T}=-10^{\circ} \mathrm{C}\right)$ after some of the gully formation experiments.

252 Using this protocol a dry layer of sand on top of the frozen substrate was formed. After one week,

253 the dry layer thickness reached more than $1 \mathrm{~cm}$ depth.

254 We varied the thawed layer water content in two ways: firstly to decrease the water 255 content we simply added a dry-sand layer to the top of the frozen layer (without letting it defrost)

256 and secondly we added water to the thawed layer using a fine spray.

258 2.3.2 Description of the Mars chamber (Open University facility)

259 For the martian environment simulation experiments, the sediment bed was contained within a 260 cylindrical low pressure chamber $2 \mathrm{~m}$ in length and $\sim 1 \mathrm{~m}$ in diameter. The test bed is a $1 \mathrm{~m}$ long, $2610.1 \mathrm{~m}$ deep rectangular metal tray. A $\sim 5 \mathrm{~cm}$ deep sand bed was saturated with water, leveled off 262 and then placed in the freezer onsite. After complete freezing of the material (after $\sim 15 \mathrm{~h}$ ), the 263 tray was removed and, where necessary, a defrosted layer was allowed to form. The tray was 
264 placed in the chamber and the pressure reduced to 6 mbar $(\sim 1 \mathrm{~h})$. The temperature of the frozen 265 bed, melted layer and the chamber pressure were monitored throughout.

Once the correct pressure was achieved, water was introduced from an external reservoir.

267 The pressure in the chamber was actively controlled using a vacuum pump and was maintained at 2686 mbar for the low pressure experiments. The temperature of the surface was monitored during 269 the experiments using thermocouples. Water was introduced from a pipe at the upper edge of the 270 test bed and allowed to flow down and across the sediment substrate. Thus each experiment

271 lasted between $\sim 5 \mathrm{~s}$ and $\sim 15 \mathrm{~s}$ and a total of $\sim 60 \pm 10 \mathrm{ml}$ of water was used each time (Table 2).

272 A solenoid valve within the end of the hose allowed external control over the release of water.

273 The slope was controlled and three slopes were tested $\left(15^{\circ}, 20^{\circ}\right.$ and $\left.25^{\circ}\right)$. The progress of each

274 experiment was monitored using two internal cameras and two external video devices. Photo275 documentation was performed prior, during and after each experimental run. Once the 276 experiment was complete the chamber was returned to atmospheric pressure ( 1 min) and the 277 depth of the melted layer was measured. The tray was removed for scanning to generate a full 278 elevation model of the sediment surface and to make any other additional measurements. The 279 water content of the thawed layer was kept constant in these experiments.

$281 \quad$ 2.3.3 Derivation of measured morphologic parameters

282 In order to obtain quantitative measurements of the experimental flow morphologies (Fig. 5a) we 283 scanned the surface of the sand-bed after each experiment to build a Digital Elevation Model 284 (DEM) of the gully (Fig. 5b). We applied a natural neighbor interpolation method to the point 285 cloud with a cellsize of $0.5 \mathrm{~mm}$ to produce the DEMs. The DEMs were used to calculate the total 286 volume of eroded and deposited sand. Before the experiment, the sand substrate was prepared to 
287 obtain a flat topography with a constant slope. The volume of sand eroded, or deposited, was

288 calculated by taking the difference between an estimated initial topography and the measured 289 topography generated by the flow (Fig. 5d). The initial topography was estimated by natural 290 neighbor interpolation of the topographic points with the flow area masked out. The error 291 introduced into the volume calculation by using an estimated initial surface was $\sim 0.5 \%$. We 292 calculated this error by comparing volumes derived using this technique and those based on pre293 scanning the initial surface for the same flow. Because the difference in the volumes calculated 294 using the interpolation technique and pre-scanning technique were so small, pre-scanning of the 295 bed before each experimental run was not necessary.

296 For the experiments under martian conditions performed at the Open University, the bed 297 was scanned using the David Laserscanner system (http://www.david-3d.com/). This scanning 298 system uses a 'structured light' (Winkelbach, et al., 2006) approach to generate an elevation point 299 cloud. A fixed video camera records the progress of a laser-line over a subject - the deviation of 300 the laser from a straight line allows estimation of the topography. To correct for camera distortion 301 and to provide scale, an image is first taken of known-scale calibration boards with a printed 302 black-and-white pattern. The subject is then placed between the camera and calibration boards 303 and scanning undertaken. Linear artifacts can be introduced by high ambient light conditions and 304 vibrations of the laser - these typically have an amplitude of $\sim 1 \mathrm{~mm}$. Because of the random 305 distribution of these errors, this resulted in $<0.5 \%$ error on the volumes calculated. Voids are 306 caused by steep areas of topography from which no light was received and for any topography 307 near the edge of the tray- "shadows". We used a conservative estimate of $\sim 10 \%$ for the error on 308 the volume for the martian chamber experiments to take into account these unquantified artifacts. 
310 laser scanner was used (MCA Metris). This laser scanner allows a very precise measurement of

311 the volume with a vertical uncertainty on the raw data of $\sim 0.1 \mathrm{~mm}$ and a typical horizontal

312 spacing of $<0.2 \mathrm{~mm}$ between point samples. Due to the high point density and high vertical

313 accuracy the error introduced by the scanner itself is below that introduced by the volume-

314 calculation method.

315 Using a ruler or Vernier calipers we measured the height of the levees, the width of the

316 levees, the width of the apron, the length of the apron the depth of the channel and the length of

317 the flow. The apron length was measured from the beginning of the perched channel system to

318 the end of the deposit. We estimated an error on these measurements of $\sim 0.5 \mathrm{~mm}$. We did not

319 take these measurements from the DEM, because we could more reliably identify the edges of

320 levees, channels and aprons necessary to perform the measurements using in-situ techniques.

\section{3. Results}

\subsection{Remote sensing observations of Mars: evidence for perched channels}

324 By analyzing HiRISE DEMs, we have found potential perched channels in several dune gullies 325 on Mars. On the Russell megadune we found two gullies with perched channels: they are $\sim 10 \mathrm{~m}$ 326 wide, $\sim 1 \mathrm{~m}$ deep and are perched between $1 \mathrm{~m}$ and $2 \mathrm{~m}$ above the initial dune topography (Figs. $3276 \mathrm{~b}, 6 \mathrm{~d}$ and $6 \mathrm{e})$. On the Kaiser barchan, we have identified a perched channel on the downstream 328 part of another gully (Fig. 6a and 6c). Lateral levees are well developed in the downstream part 329 where the perched channels are observed. Upstream, the channel has eroded down into the 330 substrate. It should be noted that the variations in the channels and gullies that are being 331 measured here are of a scale that is near the resolution of (and therefore noise within) the 
332 topography data. Hence, it is difficult to robustly identify the perched channels, or to search for 333 spatial patterns such as where in the channel the transition from 'normal' to 'perched' occurs. 334 Detailed examinations of perched channels require better DEMs. Nevertheless, the profiles 335 shown are indicative of the behavior of those gullies within the local area (about $5 \mathrm{~m}$ up and 336 downstream) and we therefore conclude that there is a strong possibility that perched channels 337 exist on Mars near the terminus of dune-gullies. In the following sections we report the results 338 from our laboratory simulations which elucidate conditions under which such perched channels 339 can form.

\subsection{Experimental results}

\section{$342 \quad 3.2 .1$ Levees, apron morphology and perched channel}

343 The morphologies of the flows that we have generated experimentally share some key-features 344 with martian dune-gullies (and terrestrial debris flows). A well-developed linear channel was 345 repeatedly formed (Fig. 5) and overall width varied only slightly along the length of the flows. In 346 every simulation, lateral levees were formed, because the center part of the flow progressed 347 downstream faster than the lateral part of flow, leading to the deposition of sediments. Some of 348 the eroded-sediments were also deposited at the downstream part of the flow forming a debris 349 apron. The apron was lobate in planform, sometimes with a digitate terminus, and was linked 350 continuously with the levees (e.g., Fig. 5a). 
354 was observed under terrestrial and Martian atmospheric conditions (Shakesby and Matthews, 355 2002).

In all of our experiments the debris apron was characterized by the presence of a perched

357 channel. In plan-view, it appears as a continuation of the 'normal' erosive channel, but its floor is 358 above the surrounding topography. We found that a significant proportion of the deposition 359 volume can be located below a perched channel $(\sim 5 \mathrm{~mm}$ thick and $\sim 10 \mathrm{~mm}$ wide observed on 360 Figure 11).

\subsubsection{Effect of atmospheric pressure}

363 The flows produced under Mars-like atmospheric pressure were similar in terms of overall form 364 as described in section 3.2.1. During the creation of the experimental debris flows at low 365 pressure, the water simultaneously boiled and froze as it flowed, as expected at these pressures 366 and temperatures $\left(\sim 0^{\circ} \mathrm{C}\right)$. Boiling occurred both on the surface of the thawed layer and also in the 367 water flowing down the channel. When the flow was completed, this process left small-scale pits 368 on the levees and the apron deposit (Figs. 10c and 10d). In some experiments, a few minutes after 369 the flow had stopped, some of the water contained in the apron deposit and levees froze in situ 370 although even at $\sim 6$ mbar, liquid water was observed to persist over several minutes (at least 30 371 min in some experiments), despite being unstable at such low pressure.

372 Despite these effects our results showed no significant influence of the atmospheric 373 pressure on the variation of flow-morphology with slope (Section 3.2.1, Fig. 7) and in both 374 atmospheric pressure states perched channels were observed in the downstream part of the flow 375 for all the experiments. 
378 We used a range of thawed layer water contents (between 0 and $23 \mathrm{wt} \%$ ) and a range of thawed 379 layer thicknesses ( 0 to $\sim 4 \pm 1 \mathrm{~mm}$; Table 1 ). We investigated the effect of the thawed layer's water 380 content on the overall length of the flow (Fig. 8), the volume eroded (Fig. 9a), the volume 381 deposited (Fig. 9b) and the length of the depositional zone, including any perched channel (Fig. 382 9c). In each case, increased water content in the thawed layer acts to increase the length, volume 383 eroded, volume deposited, and the length of depositional zone of the debris flow. In these plots 384 the length-scales and volumes have been normalized by the volume of water injected in order to 385 account for small volume variations. A measureable increase in the overall length of the flows is 386 observed associated with the increase of the water content of the thawed layer (Fig. 8). An 387 increase of the water content of the thawed layer by a factor 4 resulted in an increase of the flow 388 length by a factor of slightly more than 3 .

In order to take into account the $3 \mathrm{D}$ dimension of the morphology and to enable 390 comparison with features at field-scale, we included the effect of the width $w$ and the height $h$ of 391 the flow (Fig. 8b). The linear dimensions $(L>>w)$ and the aspect ratio $(h \sim w)$ were taken into 392 account during the graphical analysis. The influence of the water content of the thawed layer 393 persists when taking into account the 3D geometry of the flows. With the intention of comparing 394 our results to martian gullies, we have dimensioned the experimental results obtained under 395 terrestrial conditions to account for the lower martian gravity (Fig. 8c).

As a consequence of the positive relationship between the flow-length and the water 397 content of the thawed layer, we observed that the volume of the eroded and deposited material 398 were also dependent on the water content of the thawed layer. More precisely, the results showed 399 that the increase in the volume of material eroded and deposited correlated to an increase of the 
water content of the thawed layer (Figs. 9a and 9b). This influence of the water content of the

401 thawed layer on the volume of material eroded or deposited only seems to come into effect at 402 higher water contents (>15\% in weight).

403 An increase in the water content of the thawed layer also causes an increase in the length 404 of the deposition zone (perched channel + apron) as shown in Figure 9c. However, the length of 405 the deposition zone increases more slowly than the overall length of the channel, so as a ratio of 406 debris apron length to channel length, the debris apron decreases in relative size with increasing 407 water content.

$409 \quad$ 3.2.4 Eroded and deposited volumes

410 The deposition volume of the experimental flows ranges from $\sim 2.2 \times 10^{5} \mathrm{~mm}^{3}$ to $\sim 1.1 \times 10^{6} \mathrm{~mm}^{3}$ 411 and the erosion volume ranges from $\sim 1.8 \times 10^{5} \mathrm{~mm}^{3}$ to $\sim 9.8 \times 10^{5} \mathrm{~mm}^{3}$ (Table 1 ). The volume of 412 deposited material was always greater than the volume of eroded material (Fig. 10) under 413 terrestrial atmospheric conditions, but under martian atmospheric conditions (with volumes < $4143 \times 10^{5} \mathrm{~mm}^{3}$ for nearly half the experiments) the erosion volumes were greater than the deposition 415 volumes.

416 Following re-measurement of the flow volumes after a period of desiccation $(\sim 70 \mathrm{hrs}), \mathrm{a}$ 417 decrease in deposition volume was observed. Thus the discrepancy between the volume of 418 eroded and deposited material decreased (Fig. 11). The desiccation of the wet thawed layer also 419 modified the general appearance of the deposit area: reducing slopes and blurring the boundary 420 between the flow and the surrounding topography (Fig. 11). This demonstrates the role water and 421 ice contained in the deposit plays in augmenting the depositional volume. 


\section{Discussion}

$424 \quad 4.1$ Mobility of flows with thawed layers

425 Our experiments demonstrated that the percentage of water contained in the thawed layer has an 426 influence on the flow mobility. For example, an increase of $10 \%$ in the thawed layer water 427 content causes an increase of $40 \%$ in the non-dimensional length of the flows (Fig. 8a). The non428 dimensional length corresponds to the length of the flow $(L)$ divided by the cube-root of the 429 volume of water injected from the pipe $\left(V_{\text {water }}^{1 / 3}\right)$. Hence, we account for the small variations in 430 the volume of water injected between experiments and only the effects of the water in the thawed 431 layer are considered. Thus it is determined that high levels of water content in the thawed layer 432 can significantly increase the runout of a flow for any given initial volume of water.

433 The increased mobility of the flow with an increased proportion of water in the thawed 434 layer can be accounted for in two ways: firstly the addition of water causes a decrease in the 435 flow's viscosity (Coussot, 1993; Remaitre et al., 2005) and hence a longer runout, and secondly it 436 causes a decrease in infiltration capacity of the substrate, reducing loss by infiltration, which 437 again leads to longer runout. Dealing with the first mechanism, there are two ways in which the 438 thawed layer can contribute additional water over the length of the flow. The first is by the 439 erosion of the thawed layer (and hence assimilation of both sand and water into the flow) along 440 the path; the second is by gravity-driven drainage of the water from the thawed layer immediately 441 surrounding the flow into the newly excavated void of the channel. We infer drainage of the 442 thawed layer into the channel, because we observed water flowing into the channel after the main 443 source had been switched off in our experiments. Hence, the water involved in the flow444 formation is not necessarily sourced from the alcove area. For our experiments we have found 445 that a significant part of the liquid ( $40 \%$ of the volume, for a water content of the thawed layer 
446 of $20 \%$ ) could come from the material eroded by the flow. A basic estimation of the

447 concentration of liquid in the flow can be estimated using the equation

$$
C_{\mathrm{w}}=\left[V_{\text {fluid active layer }}+V_{\text {fluid injected }}\right] /\left[V_{\text {erosion }}+V_{\text {fluid active layer }}+V_{\text {fluid injected }}\right]
$$

Here we obtain a liquid concentration between 0.48 and 0.58 where the water content of

450 the thawed layer ranges between $\sim 20 \%$ and $23 \%$. This liquid concentration is comparable to

451 concentrations used in a previous experimental study concerning the runout distance of debris

452 flows (D'Agostino et al., 2009). On Earth, a typical solid fraction of $50 \%$ to $90 \%$ has been

453 estimated for debris flows (Corominas et al., 1996; Iverson, 1997), these values are also in line

454 with our experiments.

455 The second mechanism promoting the mobility of the flow with increased water content

456 is that of decreasing infiltration capacity. In these experiments the presence of a frozen layer

457 already introduces a barrier to infiltration, however if the thawed layer is not saturated, some

458 water is lost by infiltration into this layer. However, if this layer is saturated, water is not lost and

459 surface flow is favored. An increase of the length of the deposit area (perched channel + apron)

460 with the increase of the water content into the thawed layer is observed (Fig. 9c) demonstrating

461 that, where a perched channel is formed above the thawed layer, it is particularly difficult for 462 water within the flow to infiltrate.

463 An increase in water content of the thawed layer increases the water content in the flow 464 and engenders a decrease of the friction at the base of the flow, allowing the flow to propagate 465 further (De Blasio, 2011). This is not simply because of the decreased viscosity of the flow. 466 Increased pore pressures develop in the wet thawed layer as it is overridden and progressively 467 entrained by the flow (Iverson et al., 2011). The increased pore pressure facilitates progressive 468 scour of the bed, reduces basal friction and causes a significant flow-momentum growth (Iverson 
et al., 2011). Iverson et al. (2011) noted that there was a threshold response of bed-sediment pore-

470 pressures on debris flow loading, whereby if the water content falls below a certain value then air

471 escapes too easily to maintain pore pressures. This effect could explain the threshold at $\sim 15 \%$

472 water content in Figure 9. The water content influences on the volume deposited and eroded can

473 be described by (1) a linear model $\left(\mathrm{R}^{2} \sim 0.6\right)$, (2) an exponential model $\left(\mathrm{R}^{2}>0.6\right)$, (3) a linear

474 model with a threshold at $\sim 11 \%\left(0.23<\mathrm{R}^{2}<0.27\right)$. Further investigations are needed to determine

475 the best model. Aquaplaning effects could also be at play and have been proposed to explain the

476 mobility of landslides on Mars (De Blasio, 2011). The water flow above the thawed layer could

477 permit the destabilization of the grains by a decrease of the water suction into the thawed layer

478 and the rapid drainage of the thawed layer.

479

\subsection{Comparability and transferability of results to Mars}

The aim of this study was to understand better the apparent lack of terminal deposits of

482 dune-gullies on Mars, but not to reproduce exactly every aspect of their dynamics and 483 morphology. Therefore we conducted simplified experiments using homogeneous sand, 484 smoothed topography and calibrated input whereas in reality the grain size and topography could 485 be more heterogeneous and the input parameters highly variable.

486 As a consequence, the full complexity of real gullies or debris flows cannot be reproduced 487 by our experiments. For example, heterogeneity in a flow's grain size distribution can trigger size 488 segregation effects, which are apparent in the terminal deposits of debris flows on Earth (Johnson 489 et al., 2012). In our experiments this effect was limited by the homogenous grain size and by the 490 presence of liquid water which can act to diminish the migration of large particles to the flow 491 perimeter (Pouliquen and Vallance, 1999). 
493 (Coleman et al., 2009) or even to terrestrial debris flows (D'Agostino et al., 2009). For our 494 experiments, we have calculated a Reynolds number $(\operatorname{Re}=d v \rho / \mu)$ between 2 and 750 , by using a 495 hydraulic radius $d=2 \mathrm{~cm}$, density $1000<\rho<1500 \mathrm{~kg} \cdot \mathrm{m}^{-3}$, velocity $0.038<v<0.077 \mathrm{~m} . \mathrm{s}^{-1}$, and 496 viscosity $0.001<\mu<1$ Pa.s. This range of $\mathrm{Re}$ is in the range $250<R e<650$ estimated for 497 martian gullies using the Russell dune topographic data by Jouannic et al. (2012a). Hence, it is 498 not unreasonable to compare morphological attributes between our experiments and the dune 499 gullies on Mars.

500 In our analysis of the experimental flows' runout length (Section 4.3), we have taken into 501 account the reduced gravity of Mars using non-dimensional parameters (Fig. 8c), but secondary 502 effects due to possible modification of the dynamic friction angle (Kleinhans et al., 2011; 503 Sullivan et al., 2011) have been neglected. Only the atmospheric pressure has been tested. The 504 influence of the atmosphere composition on the morphology was not tested. This probably 505 influenced the rate of evaporation, freezing and sublimation.

506 We have focused our study on wet flow over a frozen substrate. Nevertheless, dry 507 granular flows can also generate several surface features (levees, channels) superficially similar 508 to those seen in martian gullies (Shinbrot et al., 2004). During our experiments, no significant 509 sinuosity was observed, whereas this is observed in dune gullies on Mars (e.g., Mangold et al., 510 2003) and in debris flows on Earth. On Earth, topographic heterogeneity is likely to be 511 responsible for sinuosity in debris flow paths, as illustrated by a sinuous debris flow in the Vallée 512 de la Clarée (Fig. 2c, French Alps) caused by the presence of trees along its path. Hence, the lack 513 of sinuosity in our experimental flows can be attributed to the simplified topography, rather than 514 a dissimilarity of process. 
$516 \quad 4.3$ Application to martian dune gullies

517 HiRISE elevation data have been used to measure the morphology and estimate the initial water 518 volume necessary to generate gullies on the Russell megadune. These gullies are $2 \mathrm{~km} \mathrm{long,}$ 519 located on a gentle slope $\left(10-15^{\circ}\right)$, with a depth of approximately $\sim 1 \mathrm{~m}$, channel width of $\sim 10 \mathrm{~m}$, 520 levee height range between $0.5-1.8 \mathrm{~m}$ and levee width range between $\sim 3$ - $15 \mathrm{~m}$ (Mangold et al. 521 2003; Reiss et al., 2003; Jouannic et al., 2012a). The water volume necessary to produce such 522 phenomena has been estimated to be $4500-7000 \mathrm{~m}^{3}$ by Jouannic et al. (2012a), but the same 523 authors found that the volume of the reservoir located at the top of the sand dune was only of 400 $524-900 \mathrm{~m}^{3}$. This provides a conundrum. However, by using the experimental results presented here, 525 we can provide some explanations for this mis-match. If we scale our non-dimensional 526 experimental results for flow length (using the linear interpolation obtained in Fig. 8c; $G_{\mathrm{M}}=3.7$

$527 \mathrm{~m} . \mathrm{s}^{-2} ; G_{\mathrm{E}}=9.8 \mathrm{~m} . \mathrm{s}^{-2}$ ) and use a reservoir volume of $\sim 900 \mathrm{~m}^{3}$, we can obtain a gully with a length 528 of $2 \mathrm{~km}$ as observed on Russell megadune on Mars. In this calculation we assume the flow 529 propagates in a channel $\sim 10 \mathrm{~m}$ wide, above a sandy substrate containing $30 \%$ of liquid water in an 530 upper thawed layer of $\sim 1 \mathrm{~m}$ in thickness, with a slope of $10^{\circ}$. In other words, over the relatively 531 shallow slope of dunes on Mars, with a relatively small initial volume of liquid, a flow could 532 propagate over much longer distances than expected for dry sand, if it occurs on a substrate 533 composed of wet sediments overlying a frozen base. However, the conditions that produced such 534 an active layer (obliquity or seasonal activity), are beyond the scope of this paper.

$536 \quad 4.4$ Deposit morphology and degradation of morphology

537 On Earth and on Mars, many gully morphologies result from the succession of multiple flow 
538 events and the progressive accumulation of sediments in the downstream part of gullies (Figs. 1a 539 and 1d). In these cases, a large terminal debris apron deposit can be observed (Hugenholtz et al., 540 2007) and such an apron can be obtained experimentally by superposition of successive flow 541 events. There is also a less abundant category of debris flow morphologies that is characterized 542 by reduced terminal deposit or the apparent lack of deposit. On Earth, these small terminal 543 deposits of debris flows can be found in cold and periglacial environment on scree slopes (French 544 Alps, Jomelli et al., 2007) or on slopes of volcanoes with very fine sediments (Fig. 1b, Italy). On 545 Mars, small terminal deposits have been found in gullies on the inner wall of Tooting crater (Fig. 546 1e) and in dune gullies (e.g. Matara and Russell crater dunes studied here), which we show also 547 have a perched channel in the downstream part of the gullies. Our results show that small 548 terminal deposits can be simulated experimentally under periglacial conditions using an ice-rich 549 substrate composed of fine sand $(200-250 \mu \mathrm{m})$ beneath a thin thawed layer containing a high 550 proportion of water $(\sim 10-20 \%$ in weight) under low $(6$ mbar) or ambient ( 1 bar) pressure 551 conditions (Fig. 10). A large proportion of the terminal deposits are located in the area where 552 perched channels develop, hence can easily be confused for erosional morphology in plan-view. 553 The aspect ratio between the width $w$ and the length $L$ of deposits (perched channel + apron) for 554 our experiments ranges between $1 / 22<W / L<1 / 10$, which is very similar to that of gullies on the 555 Russell crater megadune ( 1/20; Jouannic et al., 2012) or on Kaiser crater dunes ( 1/6; Gargani 556 et al., 2012).

557 Our experiments show that the degradation of the flow morphology, due to the 558 desiccation of the surface over time, decreases the measured volume of the deposits and degrades 559 their appearance (Fig. 11). The fresh morphology of the experimental flows is characterized by 560 complex lobate features with steep local slopes on the inner and outer parts of the levees: such 
561 features are not observed on martian dune gullies. After desiccation, we observed that the 562 deposits lose their cohesion, becoming smoother and less complex (Fig. 11b). This is a direct 563 result of the angle of repose (i.e. angle of friction) for dry sand being smaller than the angle of 564 repose for wet sand (Rist et al., 2012). Hence, the sand grains are displaced by their own weight 565 and compaction occurs reversing some of the decompaction that took place with erosion (Fig. 566 10). This initial decompaction is a result of non-optimal reorganization of the sand grains 567 (presence of bubbles and space between grains; Fig 10d), which then settle on desiccation. 568 Despite the loss of fine-scale morphology of our experimental flows during desiccation, they 569 retained the topographic signature of levees and perched channels (Figs. 11c and 11d). The 570 change in morphology of our experimental flows on dessication renders them more similar to the 571 dune gullies observed on Mars. Hence, a lack of some of the fine-scale morphologies exhibited 572 by our experimental flows in the martian examples could be simply due to desiccation processes.

573 In addition the loss of definition of the outer-edge of the levees could explain why perched 574 channels had not been previously identified on martian dune gullies.

\section{5. Conclusions}

577 In spite of the numerous processes that could explain the formation of gullies and their dynamics 578 (e.g. runoff, debris flows, granular flows, sliding $\mathrm{CO}_{2}$ blocks), we focus in this work on the role 579 of liquid contained in the substrate as well as on the liquid flow and choose to experimentally test 580 the plausibility of this hypothesis. The results of this work do not rule out the possibility that 581 other processes could have formed linear gullies on martian dunes. In conclusion, this work 582 demonstrated that:

583 - The presence of a thin thawed or water-rich layer above a sedimentary substrate 
containing ground ice could explain why dune gullies on Mars and other debris flows on Earth have small terminal deposits, long runout distances (for relatively low slopes) and the presence of a 'perched' channel.

- We suggest that water from the thawed layer is incorporated progressively into the flow during progression, which reduces its viscosity. Furthermore, the presence of high water content in the thawed layer reduces infiltration of the flow into it, and possibly reduces friction at the base of the flow. These act to increase the runout length for a given initial volume of water. This additional source of water could explain the extremely long runout of dune gullies on Mars, compensating for their small upslope reservoir.

- Although absolute apron length increases with water content in the thawed layer, this effect is less than the increase in the length of the entire flow. Hence, fractional debris apron length decreases with the water content of the substrate. This could provide another explanation for the abbreviated terminal deposits observed in martian dune gullies.

- Atmospheric pressure seems to have little influence on the length, apron-width and levee aspect ratio of the simulated debris flows.

- Our study highlights the potential role of post-emplacement degradation on the morphology of debris flows in sand. Post-formation desiccation can decrease the volume of the flow, and 'blur' the outer margins of the levees, making them hard to identify in remote sensing images.

- The apparent small size of the terminal deposits associated with martian dune gullies is also a function of observational bias: the presence of a perched channel, which is a depositional feature, cannot be detected in plan-view images. If many dune gullies possess perched channels, this has a bearing on potential formation hypotheses, as 'dry' 
formational hypotheses are based on the assumption that such gullies have truncated terminal deposits.

- Future studies should aim to use the highest quality DEM data to search for more evidence for perched channels, and to explore how the balance between erosion and deposition of sediment evolves along flow. This will help constrain formation mechanisms for dune gullies on Mars.

613

614 Acknowledgement: This work is supported by "Programme National de Planétologie" from the 615 CNRS-INSU and the CNES-MarsExpress program and the HRSC team for providing the data. 616 G.J., J.G. and S.J.C. received a Europlanet transnational access grant for the experiment in the 617 OU Mars Chamber. We thank Laureen Fenech for her technical support in the cold room (Orsay, 618 Univ. Paris Sud) during 4 months in 2011. We thank A. Lucas for the compilation of the Russell 619 dune DTM. LiDAR and aerial photography data for the Ísafjörður site in northwestern Iceland 620 were obtained from the UK Natural Environment Research Council Airborne Research and 621 Survey Facility (NERC ARSF) project IG13/11, PI: Susan Conway. The authors thank the two 622 anonymous reviewers for their useful comments, thorough and helpful reviews. 


\section{References}

624

625 Aston, A.H., Conway, S.J., Balme, M.R., 2011. Identifying Martian gully evolution, in: Balme, 626 M., Bargery, A.S., Gallagher, C., Gupta, S. (Eds.), Martian Geomorphology. The Geological 627 Society of London, 356, 151-169.

628

629 Cedillo-Flores, Y., Treiman, A.H., Lasue, J., Clifford, S.M., 2011. $\mathrm{CO}_{2}$ fluidization in the 630 initiation and formation of Martian polar gullies. Geophys. Res. Lett. 38, L21202, 631 doi:10.1029/2011GL049403.

632

633 Chevrier, V.F., Ulrich, R., Altheide, T.S., 2009. Viscosity of liquid ferric sulfate solutions and 634 application to the formation of gullies on Mars. J. Geophys. Res. 114, E06001, 635 doi:10.1029/2009JE003376.

636

637 Christensen, P.R., 2003. Formation of recent Martian gullies through melting of extensive water638 rich snow deposits. Nature 422, 45-48.

639

640 Coe, J.A., Godt, J.W., Henceroth, A.J., 2002. Debris Flows along the Interstate 70 Corridor, 641 Floyd Hill to the Arapahoe Basin Ski Area, Central Colorado - A Field Trip Guidebook U.S. 642 Geological Survey Open-File Report 02-398.

643

644 Coleman, K.A., Dixon, J.C., Howe, K.L., Roe, L.A., Chevrier, V., 2009. Experimental simulation 645 of Martian gully forms. Planetary and Space Science 57, 711-716, doi:10.1016/j.pss.2008.11.002. 
647 Conway, S.J., Decaulne, A., Balme, M.R., Murray, J.B., Towner, M.C., 2010. A new approach to 648 estimating hazard posed by debris flows in the Westfjords of Iceland. Geomorphology 114, 556$649 \quad$ 572, doi:10.1016/j.geomorph.2009.08.015.

650

651 Conway, S.J., Balme, M.R., Murray, J.B., Towner, M.C., Okubo, C.H., Grindrod, P.M., 2011 a. 652 The indication of Martian gully formation processes by slope-area analysis. In: Balme, M., 653 Bargery, A., Gallagher, C., Gupta, S. (eds.) Martian Geomorphology, Geological Society of 654 London, Special Publications, 356, pp. 171-201, DOI: 10.1144/SP356.10.

655

656 Conway, S.J., Lamb, M.P., Balme, M.R., Towner, M.C., Murray, J.B., 2011b. Enhanced runout 657 and erosion by overland flow at low pressure and sub-freezing conditions: Experiments and 658 application to Mars. Icarus 211, 443-457.

659

660

661 Corominas, J., Remondo, J., Farias, P., Estevao, M., Zezere, J., Dias de Teran, J., Dikau, R., 662 Schrott, L., Moya, J., Gonzalez, A., 1996. Debris flow, in: Dikau, R. et al. (Eds.), Landslide 663 Recognition. John Wiley, New York, pp. 161-180.

664

665 Costard, F., Forget, F., Mangold, N., Peulvast, J.P., 2002. Formation of recent Martian debris 666 flows by melting of near-surface ground ice at high obliquity. Science 295, 110-113. 
668 Coussot, P., 1993. Rhéologie des boues et laves torrentielles - Étude de dispersions et 669 suspensions concentrées. Centre d'Étude du Machinisme Agricole des Eaux et Forêts, 670 Laboratoire de rhéologie, Grenoble, pp. 415.

671

672 Coussot, P., Meunier, M., 1996. Recognition, classification and mechanical description of debris

673 flows. Earth Sci. Rev. 40, 209-227.

674

675 D'Agostino, V., Cesca, M., Marchi, L., 2009. Field investigations of runout distances of debris 676 flows in the Dolomits (Eastern Italian Alps). Geomorphology 116, 294-304, 677 doi:10.1016/j.geomorph.2009.06.032.

678

679 De Blasio, V., 2011. The aureole of Olympus Mons (Mars) as the compound deposit of 680 submarine landslides. Earth and Planetary Science Letters 312, 126-139, 681 doi:10.1016/j.epsl.2011.09.019

682

683 Dickson, J.L., Head, J.W., Kreslavsky, M., 2007. Martian gullies in the southern mid-latitudes of 684 Mars: Evidence for climate-controlled formation of young fluvial features based upon local and 685 global topography. Icarus 188, 315-323.

686

687 Diniega, S., Hansen, C.J., McElwaine, J.N., Hugenholtz, C.H., Dundas, C.M., McEwen, A.S., 688 Bourke, M.C., 2013. A new dry hypothesis for the formation of martian linear gullies. Icarus 225, $689 \quad 526-537$.

690 
691 Ferrucci, M., Pertusati, S., Sulpizio, R., Zanchetta, G., Pareschi, M.T., Santacroce, R., 2005.

692 Volcaniclastic debris flows at La Fossa Volcano (Vulcano Island, southern Italy): Insights for 693 erosion behaviour of loose pyroclastic material on steep slopes. J. Volcanol. Geotherm. Res. 145, 694 173-191, doi:10.1016/j.jvolgeores.2005.01.013.

695

696 Gaidos, E.J., 2001. Cryovolcanism and the recent flow of liquid water on Mars. Icarus 153, 218697223.

698

699 Gargani, J., Jouannic, G., Costard, F., Ori, G.G., Marmo, C., Schmidt, F., Lucas, A., Busson, J., 700 2012. How much liquid water was there on Martian dunes? Geophysical Research Abstracts 14, 701 p. 11720.

702

703 Hartmann, W.K., 2001. Martian seeps and their relation to youthful geothermal activity. Space 704 Sci. Rev. 96, 405-410.

705

706 Hauber, E., Reiss, D., Ulrich, M., Preusker, F., Trauthan, F., Zanetti, M., Hiesinger, H., Jaumann, 707 R., Johansson, L., Johnsson, A., Van Gasselt, S., Olvmo, M., 2011. Landscape evolution in 708 Martian mid-latitude regions: insights from analogous periglacial landforms in Svalbard. In: 709 Balme, M., Bargery, A., Gallagher, C., Gupta, S. (eds.) Martian Geomorphology, Geological 710 Society of London, Special Publications, 356, pp. 111-131.

712 Heldmann, J.L., Mellon, M.T., 2004. Observations of Martian gullies and constraints on potential 713 formation mechanisms. Icarus 168, 285-304. 
715 Hoffman, N., 2002. Active polar gullies on Mars and the role of carbon dioxide. Astrobiology 2, 716 313-323, doi:10.1089/153110702762027899.

717

718 Hooper, D.M., Dinwiddie, C.L., 2014. Debris flows on the Great Kobuk Sand Dunes, Alaska: 719 Implications for analogous processes on Mars. Icarus, 230, 15-28.

720

721 Horgan, B.H.N., Bell III, J.F., 2012. Seasonally active slipface avalanches in the north sand sea 722 of Mars: Evidence for a wind-related origin. Geophys. Res. Lett. 39, L09201, 723 doi:10.1029/2012GL051329.

724

725 Hugenholtz, C.H., Wolfe, S.A., Moorman, B.J., 2007. Sand-water flows on cold-climate eolian 726 dunes: environmental analogs for the eaolian rock record and Martian sand dunes. Journal of 727 Sedimentary Research 77, 607-614, doi:10.2110/jsr.2007.063.

728

729 Ishii, T., Sasaki, S., 2004. Formation of recent Martian gullies by avalanches of $\mathrm{CO}_{2}$ frost. Lunar $730 \quad$ Planet. Sci. 35. Abstract 1556.

731

732 Iverson, R.M., Reid, M.E., Logan, M., LaHusen, R.G., Godf, J.W., Griswold, J.P., 2011. Positive 733 feedback and momentum growth during debris-flow entrainment of wet bed sediment. Nature 734 Geoscience 4., 116-121, doi:10.1038/NGEO1040.

735

736 Iverson, R.M., 1997. The physics of debris flows. Rev. Geophysics 35, 245-296. 
738 Johnson, C.G., Kokelaar, B.P., Iverson, R.M., Logan, M., LaHusen, R.G., Gray, J.M.N.T., 2012.

739 Grain-size segregation and levee formation in geophysical mass flows. Journal Of Geophysical 740 Research 117, F01032, doi:10.1029/2011JF002185.

741

742 Johnsson A., Reiss, D., Hauber, E., Hiesinger, H., Zanetti, M., 2014. Evidence for very recent 743 melt-water and debris flow activity in gullies in a young mid-latitude crater on Mars. Icarus 235, $744 \quad 37-54$

745

746 Jomelli, V., Francou, B., 2000. Comparing the characteristics of rockfall talus and snow 747 avalanche landforms in an Alpine environment using a new methodological approach: Massif des 748 Ecrins, French Alps. Geomorphology 35, 181-192, doi: 10.1016/S0169-555X(00)00035-0.

750 Jomelli, V., Brunstein, D., Grancher, D., Pech, P., 2007. Is the response of hill slope debris flows 751 to recent climate change univocal? A case study in the Massif des Ecrins (French Alps). Climate 752 Change 85, 119-137, doi :10.1007/s10584-006-9209-0.

753

754 Jouannic, G., Gargani, J., Costard, F., Ori, G.G., Marmo, C., Schmidt, F., Lucas, A., 2012 a. 755 Morphological and mechanical characterization of gullies in a periglacial environment: the case 756 of the Russell dune (Mars). Planetary and Space Science 71, 38-54, 757 doi:10.1016/j.pss.2012.07.005. 
760 investigation of gully formation under low pressure and low temperature conditions. Lunar 761 Planet. Sci. 43. Abstract 1509.

762

763 Gargani, J., Jouannic, G., Costard, F., Ori, G., Marmo, C., Schmidt, F., Lucas, A., Busson, J., 764 2012. How much liquid water was there on Martian dunes? EGU abstract, Vienna, p.11720.

Kirk, R.L., Howington-Kraus, E., Rosiek, M.R., Anderson, J.A., Archinal, B.A., Becker, K.J., 767 Cook, D.A., Galuszka, D.M., Geissler, P.E., Hare, T.M., Holmberg, I.M., Keszthelyi, L.P., 768 Redding, B.L., Delamere, W.A., Gallagher, D., Chapel, J.D., Eliason, E.M., King, R., McEwen, 769 A.S., 2008. Ultrahigh resolution topographic mapping of Mars with MRO HiRISE stereo images: 770 Meter-scale slopes of candidate Phoenix landing sites. J. Geophys. Res. 113, E00A24, 771 doi:10.1029/2007JE003000.

773 Kleinhans, M.G., Markies, H., de Vet, S.J., in't Veld, A.C., Posterma, F.N., 2011. Static and 774 dynamic angles of repose in loose granular materials under reduced gravity. Journal of 775 Geophysical Research 116, E11004, doi:10.1029/2011JE003865.

776

777 Knauth, L.P., Klonowski, S., Burt, D., 2000. Ideas about the surface runoff features on Mars. 778 Science 290, 711-712.

780 Knauth, L.P., Burt, D., 2003. Electrically conducting Ca-rich brines, rather than water, expected 781 in the Martian subsurface. Geol. Soc. Amer. Bull. 115, 566-580. 
783 Kolb, K.J., McEwen, A.S., Pelletier, J.D., 2010. Investigating gully flow emplacement 784 mechanisms using apex slopes. Icarus 208, 132-142, doi:10.1016/j.icarus.2010.01.007.

785

786 Larsson, S., 1982. Geomorphological Effects on the Slopes of Longyear Valley, Spitsbergen, 787 after a Heavy Rainstorm in July 1972. Geogr. Ann. Ser. A-Phys. Geogr. 64, 105-125.

788

789 Lanza, N.L., Meyer, G.A., Okubo, C.H., Newsom, H.E., Wiens, R.C., 2010. Evidence for debris 790 flow gully formation initiated by shallow subsurface water on Mars. Icarus 205, 103-112, 791 doi:10.1016/j.icarus.2009.04.014.

792

793 Malin, M.C., Edgett, K.S., 2000. Evidence for recent groundwater seepage and surface runoff on 794 Mars. Science 288, 2330-2335.

795

796 Mangold, N., Costard, F., Forget, F., 2003. Debris flows over sand dunes on Mars: Evidence for 797 liquid water. J. Geophys. Res. 108, 5027, doi:10.1029/2002JE001958.

798

799 Mangold, N., Mangeney, A., Migeon, V., Ansan, V., Lucas, A., Baratoux, D., Bouchut, F., 2010. 800 Sinuous gullies on Mars: Frequency, distribution, and implications for flow properties. J. 801 Geophys. Res. 115, E11001, doi:10.1029/2009JE003540. 
804 resolution digital models and orthorectified images of Mars from HiRISE and HiSCI. EuroPlanet 8055 , Abstract 1380 .

806

807 McDonald, R, Andersen R.S., 1996. Constraints on eolian grain flow dynamics through 808 laboratory experiments on sand slopes. Journal of Sedimentary Research, v.66, 642-653.

809

810 McEwen, A.S., Hansen C.J., Delamere, W.A., Eliason, E.M., Herkenhoff, K.E., Keszthetyi, L., 811 Gulick, V.C., Kirk, R.L., Mellon, M.T., Grant, J.A., Thomas, N., Weitz, C.M., Squyres, S.W., 812 Bridges, N.T., Murchie, S.L., Seelos, F., Seelos, K., Okubo, C.H., Milazzo, M.P., Tornabene, 813 L.L., Jaeger, W.L., Byrne, S., Russell, P.S., Griffes, J.L., Martínez-Alonso, S., Davatzes, A., 814 Chuang, F.C., Thomson, B.J., Fishbaugh, K.E., Dundas, C.M., Kolb, K.J., Banks, M.E., Wray, 815 J.J., 2007. Mars Reconnaissance Orbiter's High Resolution Imaging Science Experiment 816 (HiRISE). J. Geophys. Res. 112, E05S02, doi:10.1029/2005JE002605.

818 Morris, A.R., Mouginis-Mark, P.J., Garbeil, H., 2010. Possible impact melt and debris flows at 819 Tooting Crater, Mars. Icarus 209, 369-389, doi:10.1016/j.icarus.2010.05.029.

820

821 Musselwhite, D.S., Swindle, T.D., Lunine, J.I., 2001. Liquid $\mathrm{CO}_{2}$ breakout and the formation of 822 recent small gullies on Mars. Geophys. Res. Lett. 28, 1283-1285.

823

824 Pelletier, J.D., Kolb, K.J., McEwen, A.S., Kirk, R.L., 2008. Recent bright gully deposits on Mars: 825 Wet or dry flow? Geology 36, 211-214, doi: 10.1130/G24346A. 
827 Pouliquen, O., Vallance, J.W., 1999. Segregation induced instabilities of granular fronts. Chaos $8289,621-630$.

829

830 Reiss, D., Jaumann, R., 2003. Recent debris flows on Mars: Seasonal observations of the Russell

831 Crater dune field. Geophys. Res. Lett. 30, doi: 10.1029/2002GL016704.

834 Rist, A., Philips, M., Springman, S.M., 2012. Inclinable shear box simulations of deepening 835 active layers on perennially frozen scree slopes. Permafrost and periglacial processes 23., 26-38, 836 doi: 10.1002/ppp.1730.

837

838 Sattler, K., Keiler, M., Zischg, A., Schron, L., 2011. On the connection between debris flow 839 activity and permafrost degradation: a case study from Schnalstal, South Tyrolean Alps, Italy. 840 Permafrost and Periglacial processes 22, 254-265, doi:10.1002/ppp.730.

842 Shabesky, R.A., Matthews, J.A., 2002. Sieve deposition by debris flow on a permeable substrate, 843 Leirdalen, Norway. Earth Surface Processes and Landforms 27, 1031-1041, 844 doi: 10.1002/esp.390.

846 Shinbrot, T., Duong, N.H., Kwan, L., Alvarez, M.M., 2004. Dry granular flows can generate 847 surface features resembling those seen in Martian gullies. PNAS 101, 8542-8546, 848 doi:10.1073/pnas.0308251101. 
850 Sullivan, R., Anderson, R., Biesiadecki, J., Bond, T., Stewart, H., 2011. Cohesions, friction 851 angles, and other physical properties of Martian regolith from Mars Exploration Rover wheel 852 trenches and wheel scuffs. J. Geophys. Res. 116, E02006, doi:10.1029/2010JE003625. 853

854 Sutton, S.L.F., McKenna N Neuman, C., Nickling, W., 2013a. Lee slope sediment processes 855 leading to avalanche initiation on an Aeolian dune. J. Geophys. Res. 118, 1754-1766, 856 doi.10.1002/jgrf.20131.

857

858 Sutton, S.L.F., McKenna Neuman, C., Nickling, W., 2013b. Avalanche grainflow on a simulated 859 Aeolian dune, J. Geophys. Res. 118, 1767-1776, doi.10.1002/jgrf.20130.

860

861 Treiman, A.H., 2003. Geologic settings of Martian gullies: Implications for their origins. J. 862 Geophys. Res.: Planets 108, doi:10.1029/2002JE001900.

863

864 Védie, E., Costard, F., Font, M., Lagarde, J.L., 2008. Laboratory simulations of Martians gullies 865 on sand dunes. Geophys. Res. Lett. 35, L21501, doi:10.1029/2008GL035638.

867 Williams, K.E., Toon, O.B., Heldmann, J.L., Mellon, M.T., 2009. Ancient melting of mid868 latitude snowpacks on Mars as a water source for gullies. Icarus 200, 418-425.

870 Winkelbach, S., Molkenstruck, S., Wahl, F., 2006. Low-Cost Laser Range Scanner and Fast 871 Surface Registration Approach, in: Franke, K., Müller, K.-R., Nickolay, B., Schäfer, R. (Eds.), 
872 Pattern Recognition, Lecture Notes in Computer Science. Springer Berlin Heidelberg, pp. 718873728. 


\section{$874 \quad$ Figure captions}

875

876 Figure 1. Morphological comparison between terrestrial gullies and martian analogous as a 877 function of the apron size. (a) Debris flows in the French Alps; (b) View of debris flows at La 878 Fossa Volcano (Vulcano island, Italy) with small aprons (Figure from Ferrucci et al., 2005); (c)

879 Gullies without final deposit on Earth (Photo: O. Hungr); (d) Martian gullies on slope of an 880 impact crater (HiRISE image ESP_011727_1490); (e) Flow with digitated small aprons in the 881 interior of Tooting crater (Morris et al, 2010); (f) Gullies without final deposit on the Russell 882 megadune on Mars (HiRISE image PSP_007229_1255). HiRISE images credit: 883 NASA/JPL/UofA.

Figure 2. Field images of debris flows in the French Alps (Clarée valley). (a) A V-shape channel 887 profile is visible in the upstream part where high energy occurred and erosion is documented ; 888 (b) a perched channel with a U-shape is present in the downstream part of the gully, the cross 889 section (red line) showed that the bottom of the channel is higher in the topography of the slope 890 than the base surface (black dashed line); (c) the foot of the trees located inside the channel of the 891 gully are covered by the sediments deposited under the perched channel.. Photos taken by G. 892 Jouannic and J. Gargani.

895 Figure 3. Aerial images and airborne laser altimeter (LiDAR) data taken in summer 2013 for 896 fresh debris flows located near Ísafjörður in NW Iceland in the vicinity of flows studied by 
897 Conway et al. (2010). Neither of these flows have a topographic signature in the data acquired in 8982007 by Conway et al. (2010). The scale and orientation of each panel is the same as indicated in 899 (c). The black arrows indicate the direction of the flow. (a) Orthorectified aerial image of a small 900 debris flow on a talus slope within a cirque. (b) Shaded relief image of the LiDAR data for (a), 901 with the locations of cross sections A and B marked. White dotted lines are $10 \mathrm{~m}$ contours. The 902 data from these cross sections are shown on the right. (c) Orthorectified aerial image of a small 903 debris flow above the town of Ísafjörður, confined to the unvegetated loose talus on the upper 904 slopes. (d) Shaded relief image of the LiDAR data for (c), with the locations of cross sections C 905 and D marked. White dotted lines are $10 \mathrm{~m}$ contours. The data from these cross sections are 906 shown on the right.

Figure 4. Pictures of the two experimental facilities used to simulate gullies. (a) Mars Chamber in 910 the Open University; (b) Experimental tray containing the frozen bed in the Cold room 911 (Université Paris-Sud, France).

914 Figure 5. Experimental results of gullies simulated in the cold room. (a) Example two 915 experimental flows performed in the cold room at Orsay with similar conditions (slope $=25^{\circ}$; 916 volume of water used $=60 \pm 10 \mathrm{ml}$; flow rate $=4,6 \mathrm{ml} / \mathrm{s}$; thawed layer thickness $=4 \mathrm{~mm}$; water 917 content of $19 \%$ in the thawed layer); (b) Perspective hill shaded view of the DEM of the same 918 experiment created using the laser scanner data, a calculation of the erosion depth and deposition 919 thickness has been performed on the gully on the left; (c) Diagram illustrating the configuration 
920 in cross-section of the frozen bed and the wet thawed layer; (d) Schematic cross section of the 921 deposition morphologies (levees) and erosion morphologies (channel) related to the experimental 922 flows.

925 Figure 6. Extraction of topographic cross sections in the downstream part of martian dunes 926 gullies. (a) Image of a gully at the surface of a barchans dune located inside the Kaiser crater 927 (HiRISE image PSP_006899_1330); (b) Image of gullies at the surface of the megadune located 928 inside the Russell crater (HiRISE image PSP_007229_1255); (c), (d) and (e) Topographic cross 929 sections from the downstream part of the 3 channels, showing that the channel is elevated above 930 the surface of the dune. The final deposits of the gully are concentrated in the levee and under the 931 channel. The topography is extracted from the HiRISE DEM 932 (DTEEC_006899_1330_006965_1330_U01) for the cross section (c) and from our HiRISE DEM 933 (made by A. Lucas at Caltech) for the two cross sections (d) and (e). HiRISE image credit: 934 NASA/JPL/UofA.

937 Figure 7. Comparison between the morphology of the experimental flows performed at terrestrial 938 atmospheric pressure and at low martian pressure ( 6 mbar $)$. The trends are similar in the both 939 cases. (a) Apron width as a function of slope at martian pressure; (b) Debris apron width as a 940 function of slope at terrestrial pressure; (c) and (d) Ratio between levee height and levee width as 941 a function of slope at martian and terrestrial pressure, respectively. 
944 Figure 8. Experimental results of the water content in the active layer as a function of the gully

945 length. The water content of the thawed layer is the only parameter that changes between each 946 experiment, the other parameters are constant (slope $=25^{\circ}$, flow rate $=4.6 \mathrm{ml} \cdot \mathrm{s}^{-1}$, thawed layer 947 thickness $=\sim 4 \mathrm{~mm}$ ). The images of 4 different experiments on the right illustrate the trend of 948 increasing flow-length with increasing water content inside the thawed layer. The ruler in the 949 photographs is $50 \mathrm{~cm}$ in length for scale. (a) Effect of the water content in the thawed layer on the 950 experimental flow length. The non-dimensional parameter $\mathrm{L} /\left(\mathrm{V}_{\text {water }}^{1 / 3}\right)$ was used to allow 951 comparison between experiments under martian and terrestrial atmospheric pressure with slightly 952 different initial water volumes. (b) Effect of the water content in the thawed layer on the flow 953 geometry (i.e. aspect ratio between the width $w$, the length $L$ and the thickness $h$ of the debris 954 flow); (c) Effect of the water content in the thawed layer on the flow geometry adjusted for 955 reduced martian gravity conditions $\left(\mathrm{G}_{\mathrm{E}}\right.$ : gravity on Earth $=9.81 \mathrm{~m} \cdot \mathrm{s}^{-2} ; \mathrm{G}_{\mathrm{M}}$ : gravity on Mars $=$ $\left.956 \quad 3.71 \mathrm{~m} \cdot \mathrm{s}^{-2}\right)$.

959 Figure 9. Effect of the water content in the thawed layer on (a) the total volume of eroded and (b) 960 deposited sand. The volumes of eroded and deposited material are divided by the volume of 961 water injected from the pipe; (c) Effect of water content in the thawed layer on the length of the 962 final deposit. The black lines and the grey lines respectively correspond to the linear fits and 963 exponential fits including all the water content values, and the dashed lines correspond to the 964 linear fits including only water content values ranges from $11 \%$ to $23 \%$. The volumes of water 
used to generate the debris flows are between $50 \mathrm{ml}$ and $60 \mathrm{ml}$. Slope $=25^{\circ}$, flow rate $=4.6 \mathrm{ml} . \mathrm{s}^{-}$

$96{ }^{1}$, thawed layer thickness $=\sim 4 \mathrm{~mm}$ for all the experiments.

969 Figure 10. Plots of the volume of erosion as a function of the volume of deposition for (a) the 970 series of experiments in the cold room and (b) the series of experiments in the Mars Chamber 971 (low atmospheric pressure). The dotted line represents the volume equilibrium between the 972 erosion and the deposition and the solid line represents the calculated trend obtained from our 973 results. The error bars concerning the volume estimations in the cold room are very small $974(\sim 0.5 \%)$ and are not visible on the graph. (c) Zoomed view of the distal part of an experimental 975 flow formed at terrestrial atmospheric pressure (1 bar), the final deposits are compact and the 976 surface is smooth. (d) Zoomed view of the distal part of an experimental flow formed at martian 977 atmospheric pressure ( 6 mbar), showing the presence of small pits in the final deposits.

980 Figure 11. Effect of desiccation of the superficial layer on the morphology of experimental flows. 981 (a) Image of the morphology just after the experiment; (b) Image of the morphology 3 days after 982 the experiment; (c) and (d) Evolution of total deposition volume for the flows labelled 1 and 2 in 983 (a-b) as a function of time; (e) and (f) Evolution of the topographic cross-section from 29 June 9842012 (grey curve) to 2 July 2012 (black curve) for the flows labelled 1 and 2 in (a-b). The ruler 985 on the pictures is $50 \mathrm{~cm}$ in length for scale. Slope $=25^{\circ}$, flow rate $=4.6 \mathrm{ml} \cdot \mathrm{s}^{-1}$, initial thawed 986 layer thickness $=\sim 4 \mathrm{~mm}$. 
989 Table 1. Summary of experiments performed inside the cold room (Univ. Paris-Sud facility).

990

991 Table 2. Summary of experiments performed inside the Mars Chamber (Open University

992 facility). 


\begin{tabular}{|c|c|c|c|c|c|c|c|c|c|c|c|c|c|c|}
\hline $\begin{array}{c}\text { Experiment } \\
\text { name }\end{array}$ & $\begin{array}{c}\text { Experiment } \\
\text { date }\end{array}$ & $\begin{array}{c}\text { Slope } \\
\left({ }^{\circ}\right)\end{array}$ & $\begin{array}{c}\text { Water } \\
\text { used (ml) }\end{array}$ & $\begin{array}{c}\text { Flow rate } \\
(\mathbf{m} / \mathbf{s})\end{array}$ & $\begin{array}{c}\text { Flow velocity } \\
(\mathbf{c m} / \mathbf{s})\end{array}$ & $\begin{array}{c}\text { Thawed layer } \\
\text { thickness (mm) }\end{array}$ & $\begin{array}{l}\text { Water content in } \\
\text { the thawed layer } \\
(\%)\end{array}$ & $\begin{array}{c}\text { Total flow } \\
\text { length (cm) }\end{array}$ & $\begin{array}{c}\text { Apron width } \\
(\mathbf{c m})\end{array}$ & $\begin{array}{c}\text { Levee } \\
\text { thickness / } \\
\text { levee width }\end{array}$ & $\begin{array}{c}\begin{array}{c}\text { Final } \\
\text { deposit } \\
\text { length }(\mathrm{cm})\end{array} \\
\end{array}$ & $\begin{array}{c}\text { Flow } \\
\text { duration (s) }\end{array}$ & $\begin{array}{c}\text { Deposition } \\
\left(\mathrm{mm}^{3}\right)\end{array}$ & $\begin{array}{c}\text { Erosion } \\
\left(\mathbf{m m}^{3}\right)\end{array}$ \\
\hline 12_06_08_1g & $08 / 06 / 2012$ & 20 & 109 & 4.3 & 4.6 & 3 & 1 & 134 & 1 & 1 & 1 & 29 & 1 & 1 \\
\hline 12_06_08_1d & 08/06/2012 & 20 & 92 & 4.3 & 5.6 & 3 & 1 & 129 & 1 & 1 & 1 & 23 & 1 & 1 \\
\hline 12_06_12_1 & $12 / 06 / 2012$ & 25 & 61 & 4.6 & 5.1 & 4 & 15 & 78 & 1 & 1 & 22.0 & 15 & 55062 & -45726 \\
\hline 12_06_12_2 & $12 / 06 / 2012$ & 25 & 59 & 4.6 & 4.3 & 4 & 15 & 62 & 1 & 1 & 18.7 & 14 & 1 & 1 \\
\hline 12_06_13_1g & $13 / 06 / 2012$ & 25 & 64 & 4.6 & 5.3 & 4 & 23 & 94 & 1 & 1 & 23.0 & 18 & 109526 & -92140 \\
\hline 12_06_13_1d & $13 / 06 / 2012$ & 25 & 60 & 4.6 & 6.8 & 4 & 23 & 110 & 1 & 1 & 22.7 & 16 & 1 & 1 \\
\hline 12_06_13_2g & 13/06/2012 & 25 & 59 & 4.6 & 2.6 & 6 & 0 & 36 & 1 & 1 & 14.8 & 14 & 34069 & -27855 \\
\hline 12_06_13_2d & $13 / 06 / 2012$ & 25 & 61 & 4.6 & 2.4 & 6 & 0 & 33 & 1 & 1 & 10.6 & 14 & 29117 & -23313 \\
\hline 12_06_14_1g & $14 / 06 / 2012$ & 25 & 68 & 4.6 & 5.7 & 4 & 19 & 90 & 1 & 1 & 22.8 & 16 & 82199 & -65411 \\
\hline 12_06_14_1d & $14 / 06 / 2012$ & 25 & 71 & 4.6 & 4.9 & 4 & 19 & 100 & 1 & 1 & 21.3 & 20 & 98645 & -79150 \\
\hline 12_06_14_2 & $14 / 06 / 2012$ & 25 & 57 & 4.6 & 8.5 & 0 & 1 & 129 & 1 & 1 & 1 & 15 & 54594 & -39151 \\
\hline 12_06_15_1g & $15 / 06 / 2012$ & 25 & 60 & 4.6 & 4.6 & 5 & 19 & 68 & 1 & 1 & 1 & 15 & 1 & 1 \\
\hline 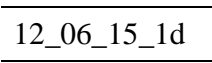 & $15 / 06 / 2012$ & 25 & 58 & 4.6 & 5.7 & 4 & 19 & 108 & I & 1 & 1 & 19 & 109890 & -98336 \\
\hline $12 \_06 \_18 \_1 \mathrm{~g}$ & $18 / 06 / 2012$ & 25 & 55 & 4.6 & 6.9 & 2 & 3 & 103 & 1 & 1 & 1 & 15 & 39292 & -29451 \\
\hline 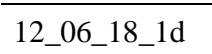 & $18 / 06 / 2012$ & 25 & 63 & 4.6 & 3.2 & 2 & 3 & 44 & 1 & 1 & 1 & 14 & 43140 & -32410 \\
\hline 12_06_25_1g & $25 / 06 / 2012$ & 25 & 56 & 4.6 & 5.9 & 2 & 7 & 89 & 1 & 1 & 1 & 15 & 1 & 1 \\
\hline 12_06_25_1d & $25 / 06 / 2012$ & 25 & 47 & 4.6 & 7.5 & 2 & 7 & 99 & 1 & 1 & 1 & 13 & 1 & 1 \\
\hline 12_06_25_2g & $25 / 06 / 2012$ & 25 & 58 & 4.6 & 2.6 & 4 & 7 & 34 & 1 & 1 & 1 & 13 & 1 & 1 \\
\hline 12_06_25_2d & 25/06/2012 & 25 & 58 & 4.6 & 3.4 & 4 & 7 & 45 & 1 & 1 & 1 & 13 & 1 & 1 \\
\hline 12_06_29_1g & 29/06/2012 & 25 & 61 & 4.6 & 4.1 & 2 & 0 & 58 & 1 & 1 & 11.2 & 14 & 37536 & -34989 \\
\hline 12_06_29_1d & $29 / 06 / 2012$ & 25 & 60 & 4.6 & 4.2 & 2 & 9 & 59 & 1 & 1 & 12.5 & 14 & 44058 & -38946 \\
\hline 12_06_29_2g & $29 / 06 / 2012$ & 25 & 49 & 4.6 & 3.9 & 4 & 9 & 45 & 1 & 1 & 14.7 & 12 & 33725 & -28629 \\
\hline 12_06_29_2d & 29/06/2012 & 25 & 56 & 4.6 & 2.8 & 4 & 9 & 37 & 1 & 1 & 11.5 & 13 & 28754 & -24490 \\
\hline 12_07_03_1g & $03 / 07 / 2012$ & 25 & 56 & 4.6 & 5.4 & 4 & 20 & 77 & 1 & 1 & 11.5 & 14 & 46699 & -45361 \\
\hline 12_07_03_1d & 03/07/2012 & 25 & 55 & 4.6 & 7.3 & 4 & 20 & 108 & 1 & 1 & 11.2 & 15 & 64996 & -63757 \\
\hline 12_07_04_1g & $04 / 07 / 2012$ & 25 & 63 & 4.6 & 2.9 & 4 & 11 & 40 & 1 & 1 & 10.7 & 14 & 39665 & -31060 \\
\hline 12_07_04_1d & 04/07/2012 & 25 & 63 & 4.6 & 3.3 & 4 & 11 & 45 & 1 & 1 & 9.2 & 14 & 34955 & -32010 \\
\hline 12_07_04_2g & 04/07/2012 & 25 & 56 & 4.6 & 3.6 & 4 & 11 & 48 & 1 & 1 & 10.6 & 13 & 37416 & -33009 \\
\hline 12_07_04_2d & 04/07/2012 & 25 & 56 & 4.6 & 3.3 & 4 & 11 & 43 & 1 & 1 & 14.1 & 13 & 31345 & -29324 \\
\hline 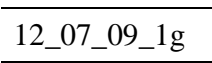 & 09/07/2012 & 25 & 61 & 4.6 & 3.4 & 3 & 4 & 46 & 1 & 1 & 13.7 & 14 & 36108 & -27047 \\
\hline 12_07_09_1d & 09/07/2012 & 25 & 62 & 4.6 & 3.2 & 3 & 4 & 45 & 1 & 1 & 14.8 & 14 & 36680 & -29063 \\
\hline 12_07_09_2d & $09 / 07 / 2012$ & 25 & 29 & 4.6 & 7.9 & 2 & 4 & 64 & 1 & 1 & 7.8 & 8 & 22451 & -17472 \\
\hline 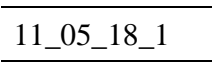 & $18 / 05 / 2011$ & 20 & 60 & 1.0 & 1.5 & 3 & wet & 93 & 6.0 & 0.3 & 1 & 62 & 1 & 1 \\
\hline 11_05_18_2 & 18/05/2011 & 20 & 120 & 0.9 & 1.0 & 5 & wet & 136 & 9.5 & 0.2 & 1 & 131 & 1 & 1 \\
\hline 11_05_18_3 & $18 / 05 / 2011$ & 20 & 120 & 0.9 & 1.2 & 5 & wet & 153 & 9.1 & 0.2 & 1 & 132 & 1 & 1 \\
\hline 11_05_19_1 & $19 / 05 / 2011$ & 20 & 60 & 0.9 & 1.0 & 5 & wet & 66 & 6.4 & 0.2 & 1 & 64 & 1 & 1 \\
\hline 11_05_19_2 & $19 / 05 / 2011$ & 26 & 60 & 1.0 & 0.8 & 5 & wet & 49 & 4.5 & 0.2 & 1 & 61 & 1 & 1 \\
\hline 11_05_20_1 & $20 / 05 / 2011$ & 26 & 94 & 1.5 & 2.2 & 1 & wet & 141 & 5.1 & 0.5 & 1 & 63 & 1 & 1 \\
\hline 11_05_20_2 & $20 / 05 / 2011$ & 26 & 98 & 1.5 & 2.5 & 4 & wet & 162 & 6.9 & 0.3 & 1 & 64 & 1 & 1 \\
\hline 11_05_23_2 & $23 / 05 / 2011$ & 20 & 120 & 1.8 & 2.4 & 3 & wet & 163 & 7.5 & 0.2 & 1 & 68 & 1 & 1 \\
\hline 11_05_26_1 & 26/05/2011 & 20 & 120 & 1.8 & 2.3 & 3 & wet & 150 & 7.0 & 0.2 & 1 & 65 & 1 & 1 \\
\hline 11_05_26_2 & 26/05/2011 & 15 & 120 & 2.1 & 1.9 & 5 & wet & 107 & 7.6 & 0.1 & 1 & 56 & 1 & 1 \\
\hline
\end{tabular}




\begin{tabular}{|c|c|c|c|c|c|c|c|c|c|c|c|c|c|c|}
\hline 11_05_27_1 & $27 / 05 / 2011$ & 26 & 120 & 1.9 & 1.7 & 5 & wet & 108 & 7.2 & 0.2 & 1 & 62 & 1 & 1 \\
\hline 11_05_30_2 & $30 / 05 / 2011$ & 26 & 120 & 1.9 & 2.4 & 3 & wet & 147 & 4.4 & 0.5 & 1 & 62 & 1 & 1 \\
\hline 11_06_09_1 & 09/06/2011 & 26 & 58 & 2.0 & 4.4 & 4 & wet & 128 & 4.6 & 0.3 & I & 29 & 1 & 1 \\
\hline 11_06_15_1 & $15 / 06 / 2011$ & 15 & 240 & 4.2 & 3.0 & 5 & wet & 172 & I & 0.1 & I & 57 & I & I \\
\hline
\end{tabular}

Table 1. Summary of experiments performed inside the cold room (Orsay facility). 


\begin{tabular}{|c|c|c|c|c|c|c|c|c|c|c|c|c|c|}
\hline $\begin{array}{l}\text { Experiment } \\
\text { name }\end{array}$ & $\begin{array}{c}\text { Experiment } \\
\text { date }\end{array}$ & $\begin{array}{l}\text { Slope } \\
\left.{ }^{\circ}\right)\end{array}$ & $\begin{array}{c}\text { Water } \\
\text { used (ml) }\end{array}$ & $\begin{array}{l}\text { Flow rate } \\
(\mathbf{m} / \mathbf{s})\end{array}$ & $\begin{array}{l}\text { Flow velocity } \\
\text { (cm/s) }\end{array}$ & $\begin{array}{c}\text { Active layer } \\
\text { thickness (mm) }\end{array}$ & $\begin{array}{l}\text { Active layer } \\
\text { composition }\end{array}$ & $\begin{array}{r}\text { Total flow } \\
\text { length }(\mathrm{cm})\end{array}$ & $\begin{array}{l}\text { Apron width } \\
(\mathbf{c m})\end{array}$ & $\begin{array}{c}\text { Levee } \\
\text { thickness / } \\
\text { levee width }\end{array}$ & $\begin{array}{c}\text { Flow } \\
\text { duration (s) }\end{array}$ & $\begin{array}{c}\text { Deposition } \\
\left(\mathrm{mm}^{3}\right)\end{array}$ & $\begin{array}{c}\text { Erosion } \\
\left(\mathrm{mm}^{3}\right)\end{array}$ \\
\hline 11_11_17_1 & 17/11/2011 & 20 & 70 & 8.0 & 4.3 & 4.0 & Wet & 47 & 4.3 & 0.3 & 10.9 & 23632 & -26162 \\
\hline 11_11_18_2 & $18 / 11 / 2011$ & 20 & 65 & 4.3 & 2.6 & 4.0 & Wet & 55 & 4.7 & 0.2 & 21.2 & 24004 & -27996 \\
\hline 11_11_21_2 & $21 / 11 / 2011$ & 20 & 60 & 6.8 & 4.1 & 4.0 & Wet & 63 & 5.3 & 0.2 & 15.5 & 19950 & -27018 \\
\hline 11_11_22_1 & $22 / 11 / 2011$ & 20 & 50 & 3.5 & 2.3 & 4.0 & Wet & 36 & 5.6 & 0.2 & 15.8 & 19044 & -20686 \\
\hline 11_11_23_2 & 23/11/2011 & 20 & 65 & 11.9 & 6.1 & 4.0 & Wet & 55 & 4.7 & 0.3 & 9.0 & 20307 & -19319 \\
\hline 11_11_25_1 & $25 / 11 / 2011$ & 26 & 55 & 13.3 & 7.1 & 3.0 & Wet & 43 & 4.1 & 0.3 & 6.0 & 13763 & -11699 \\
\hline 11_11_25_2 & $25 / 11 / 2011$ & 26 & 52 & 10.5 & 6.2 & 3.0 & Wet & 46 & 3.8 & 0.3 & 7.5 & 17346 & -11578 \\
\hline 11_11_28_2 & $28 / 11 / 2011$ & 26 & 55 & 8.6 & 6.3 & 4.0 & Wet & 49 & 3.4 & 0.3 & 7.8 & 20016 & -13755 \\
\hline 11_11_29_1 & 29/11/2011 & 26 & 40 & 6.6 & 4.4 & 2.0 & Wet & 30 & 3.7 & 0.2 & 6.9 & 18285 & -11423 \\
\hline 11_11_29_2 & $29 / 11 / 2011$ & 26 & 60 & 6.0 & 3.1 & 4.0 & Wet & 38 & 4.6 & 0.3 & 12.4 & 29543 & -19043 \\
\hline 11_11_30_1 & $30 / 11 / 2011$ & 26 & 60 & 5.6 & 3.7 & 2.5 & Wet & 52 & 3.0 & 0.3 & 14.2 & 14848 & -13287 \\
\hline 11_11_30_2 & $30 / 11 / 2011$ & 26 & 60 & 5.6 & 3.1 & 3.5 & Wet & 38 & 5.0 & 0.3 & 12.2 & 21452 & -15323 \\
\hline 11_12_01_1 & 01/12/2011 & 26 & 50 & 4.4 & 1.2 & 6.0 & Wet & 15 & 4.0 & 0.6 & 12.3 & 17226 & -6802 \\
\hline 11_12_01_2 & $01 / 12 / 2011$ & 26 & 55 & 4.9 & 2.3 & 3.0 & Dry & 30 & 4.9 & 0.2 & 13.2 & 20559 & -16028 \\
\hline 12_02_24_1 & $24 / 02 / 2012$ & 15 & 60 & 5.3 & 3.2 & 3.0 & Wet & 49 & 6.3 & 0.1 & 15.3 & 14390 & -19699 \\
\hline 12_02_27_1 & $27 / 02 / 2012$ & 15 & 50 & 5.4 & 3.6 & 4.0 & Wet & 58 & 8.2 & 0.1 & 16.3 & 9974 & -18312 \\
\hline 12_02_27_2 & $27 / 02 / 2012$ & 15 & 55 & 7.5 & 3.7 & 4.0 & Wet & 35 & 4.6 & 0.1 & 9.5 & 16064 & -11353 \\
\hline 12_02_28_1 & 28/02/2012 & 20 & 40 & 7.3 & 4.3 & 4.0 & Dry & 30 & 5.2 & 0.2 & 6.9 & 22965 & -12098 \\
\hline 12_02_28_2 & 28/02/2012 & 20 & 70 & 7.3 & 4.1 & 3.0 & Dry & 45 & 5.6 & 0.2 & 11.0 & 31921 & -26775 \\
\hline 12_03_01_1 & $01 / 03 / 2012$ & 15 & 55 & 11.2 & 6.1 & 4.0 & Wet & 41 & 4.6 & 0.1 & 6.7 & 18858 & -10781 \\
\hline 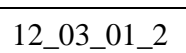 & $01 / 03 / 2012$ & 15 & 65 & 8.7 & 4.1 & 4.0 & Wet & 50 & 5.6 & 0.1 & 12.2 & 18298 & -19187 \\
\hline 12_03_05_1 & $05 / 03 / 2012$ & 20 & 70 & 13.6 & 9.7 & 3.0 & Wet & 50 & 1 & 1 & 5.1 & 17045 & -13373 \\
\hline 12_03_06_1 & $06 / 03 / 2012$ & 15 & 150 & 6.3 & 2.1 & 4.0 & Dry & 58 & 4.9 & 0.2 & 27.0 & 76292 & -45135 \\
\hline 12_03_07_1 & 07/03/2012 & 20 & 100 & 7.5 & 3.0 & 4.0 & Dry & 46 & 6.4 & 0.3 & 15.1 & 57757 & -39865 \\
\hline 12_03_08_1 & $08 / 03 / 2012$ & 20 & 45 & 6.7 & 5.1 & 4.0 & Dry & 30 & 2.9 & 0.2 & 5.8 & 20903 & -12366 \\
\hline
\end{tabular}

Table 2. Summary of experiments performed inside the Mars Chamber (Open University facility).

(a)

\footnotetext{
Table 2. Summary
}

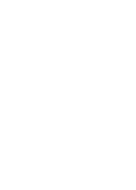




Figure (Color) 2
Click here to download high resolution image
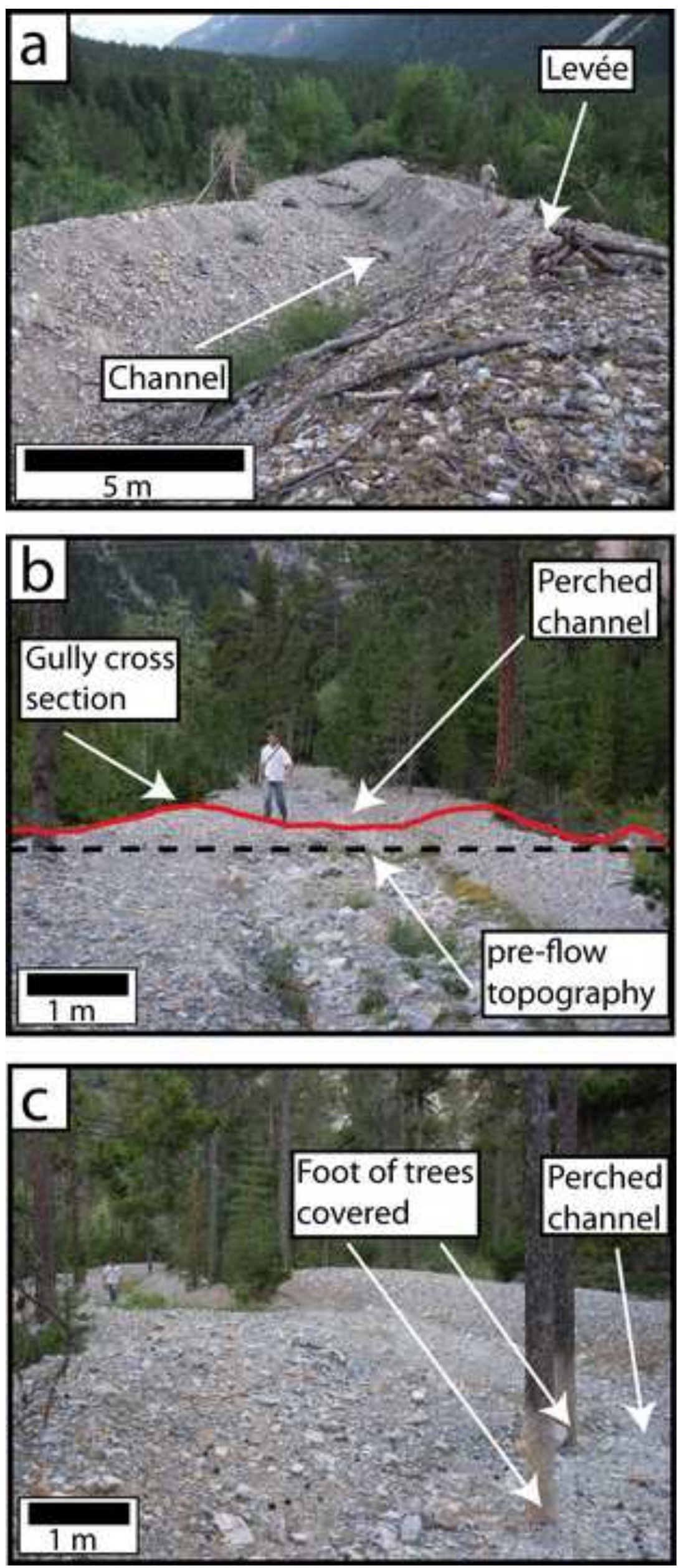

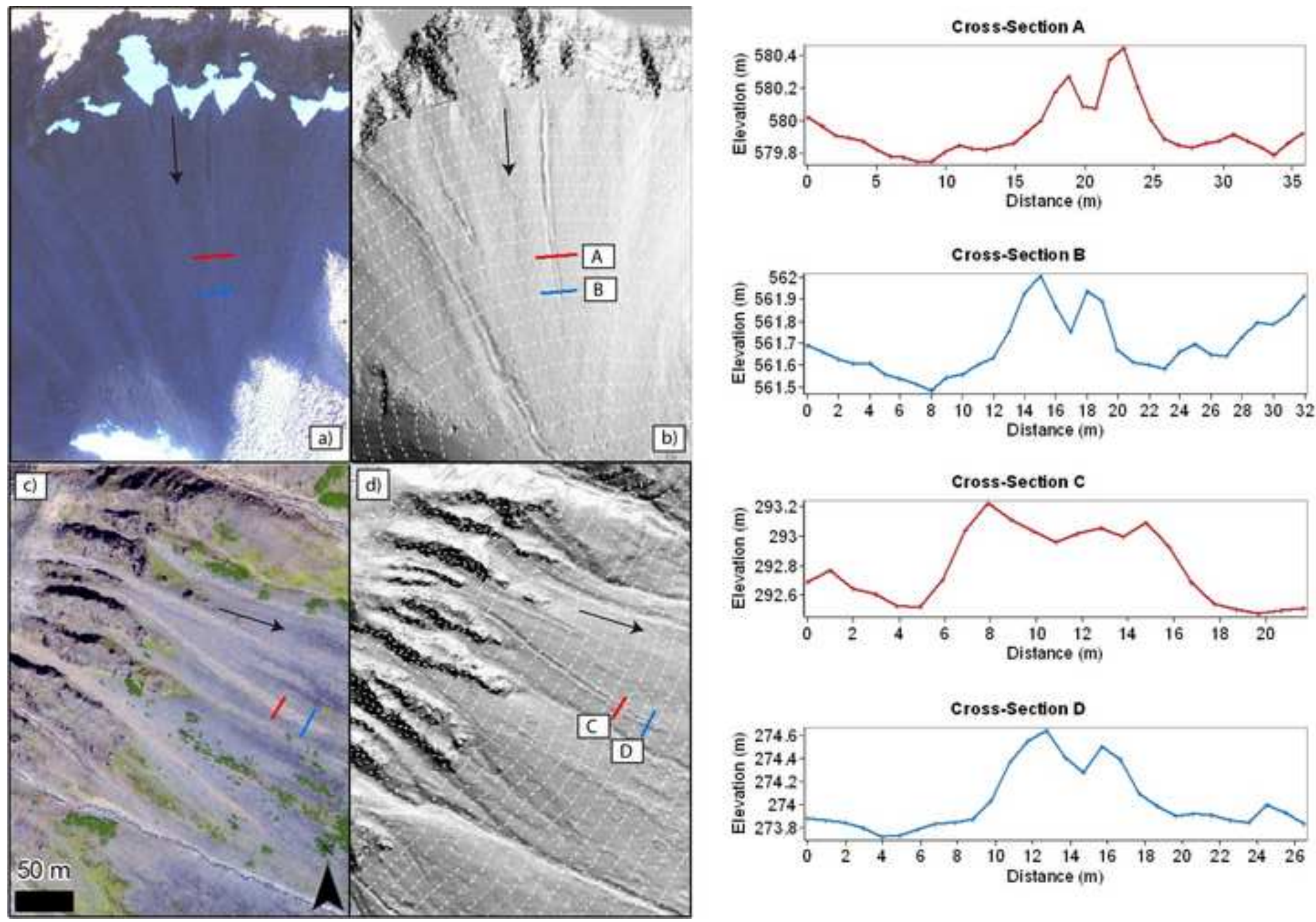

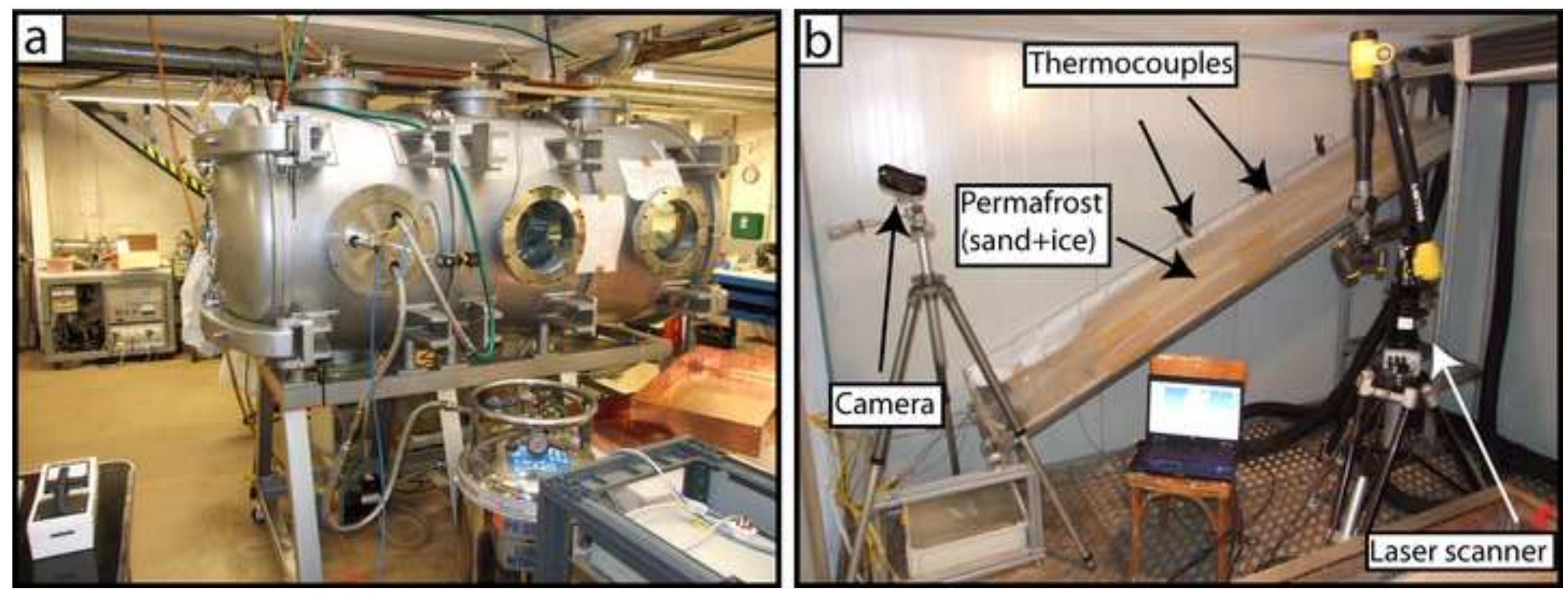

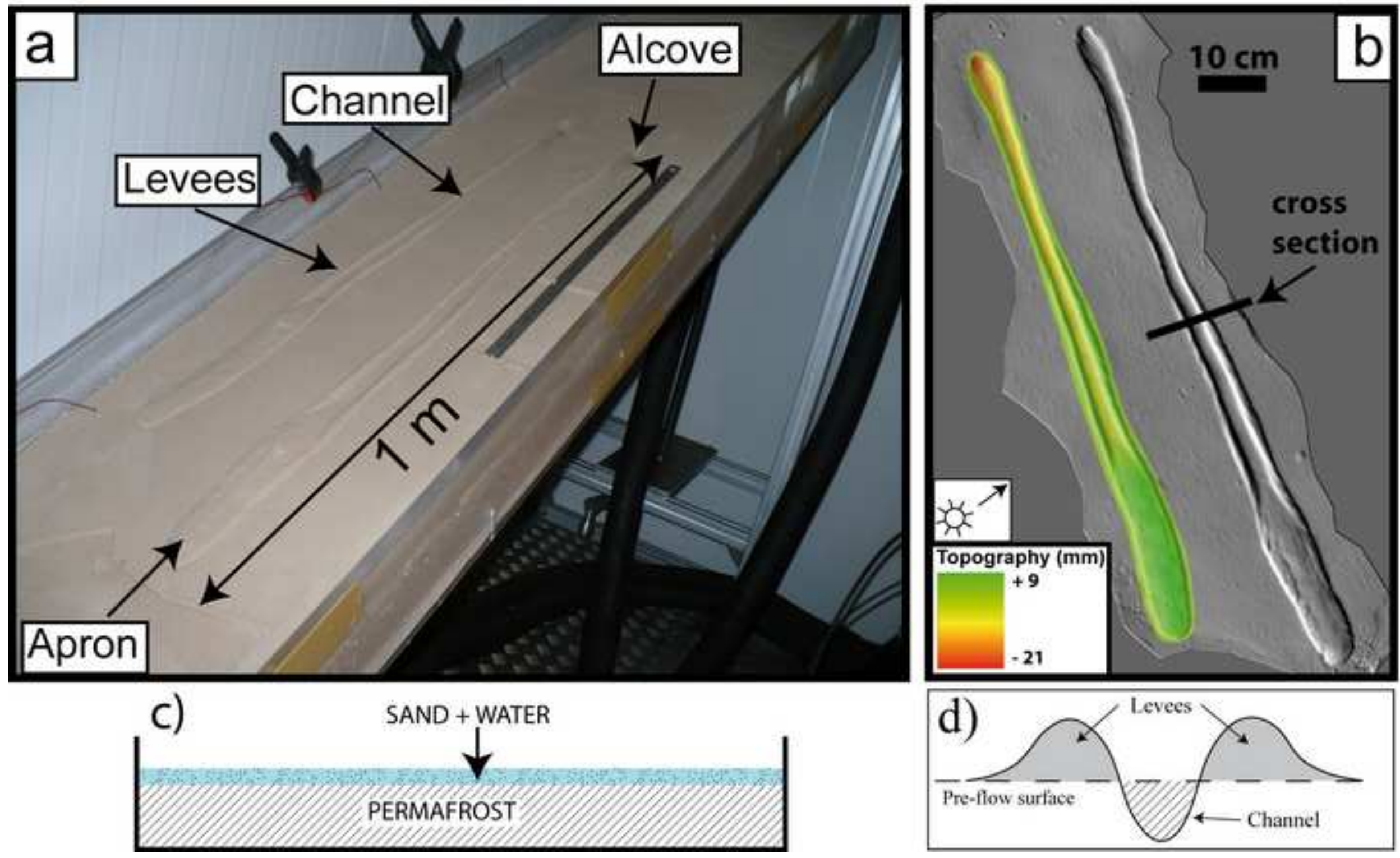
Martian pressure ( $\sim 6 \mathrm{mbar})$

a)

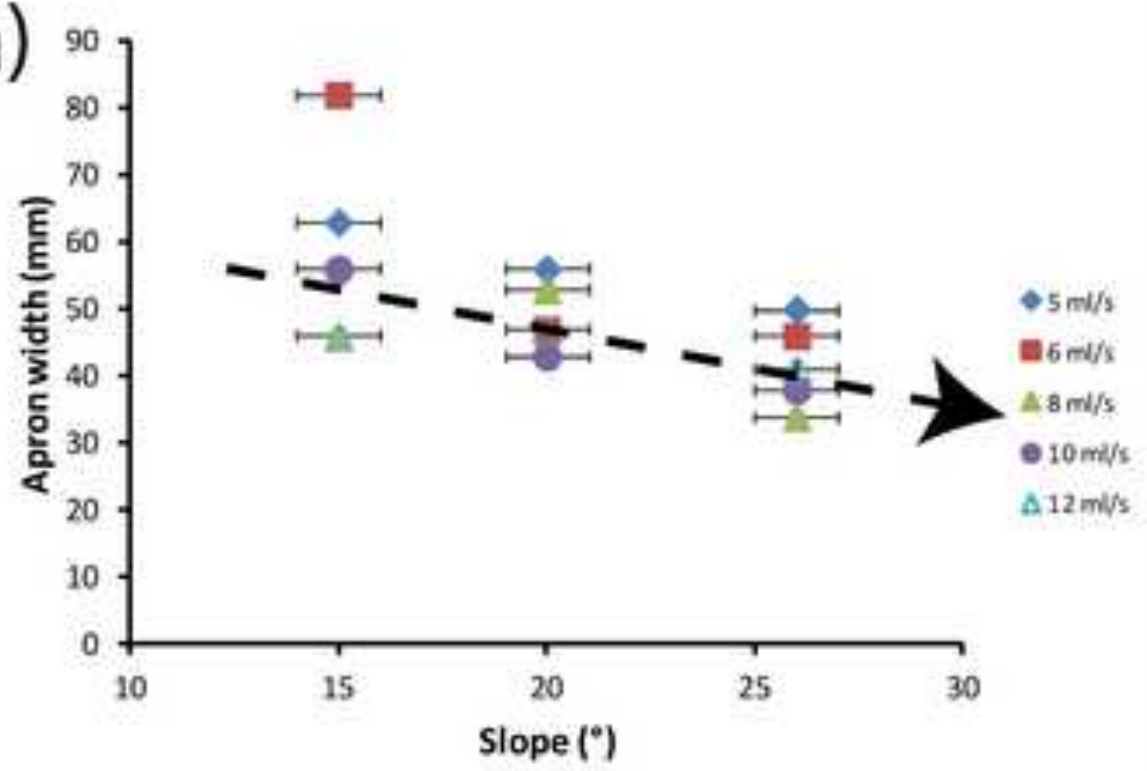

c)
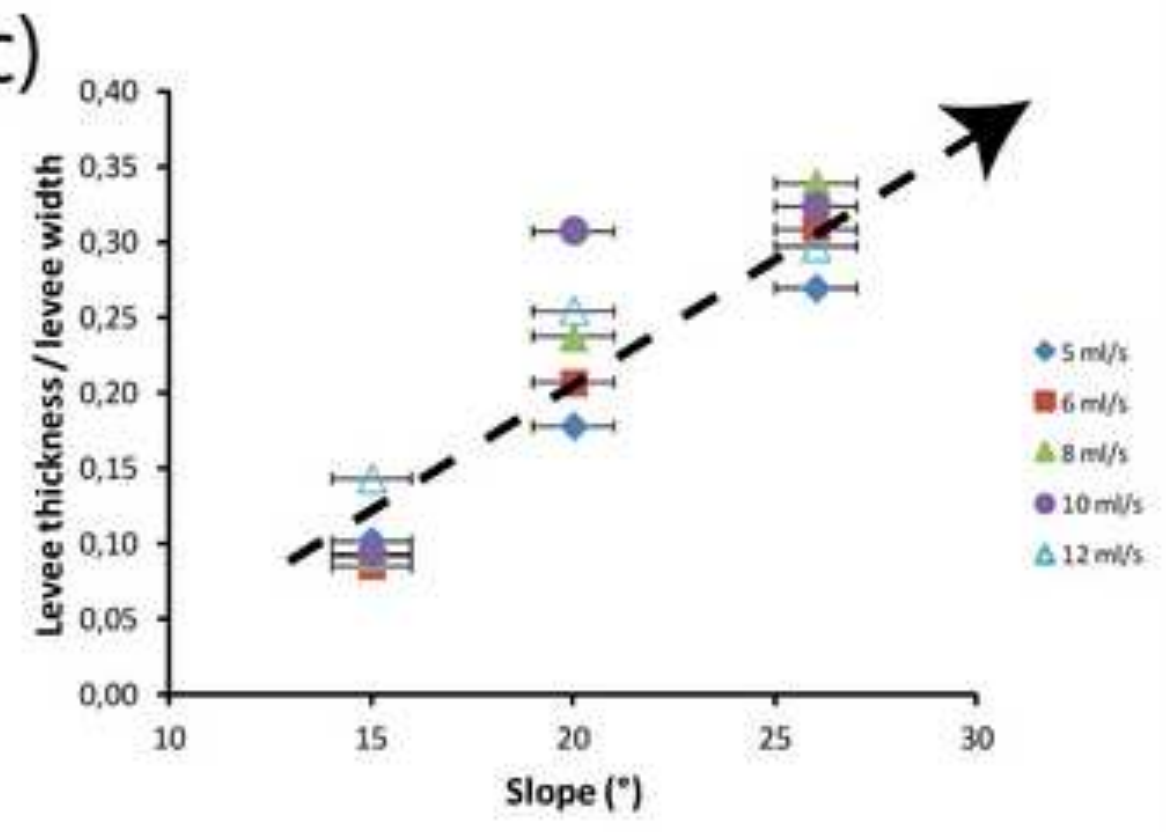

\section{Terrestrial pressure (1 bar)}

b)

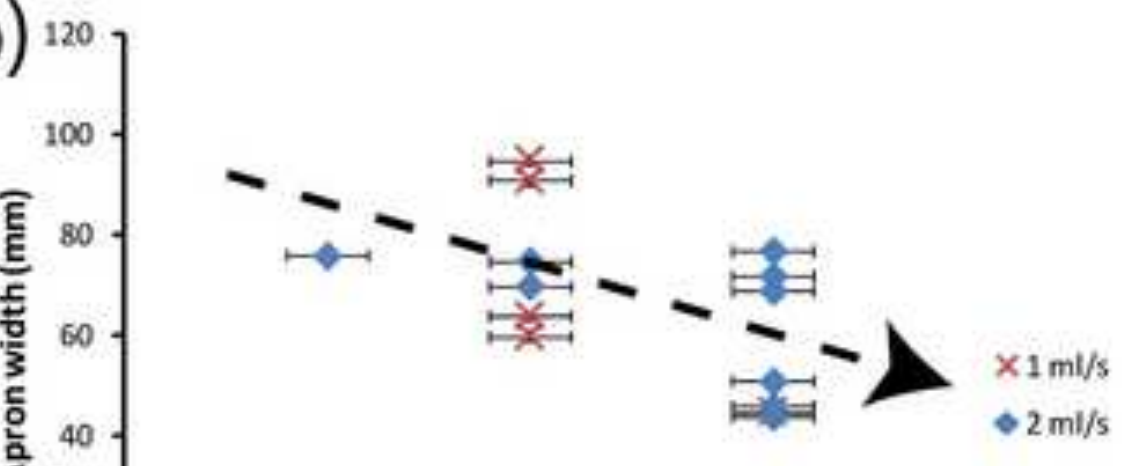

- $5 \mathrm{mid} / \mathrm{s}$

D $6 \mathrm{~m} / \mathrm{s}$

A. $8 \mathrm{md} / \mathrm{s}$

$010 \mathrm{~m} / \mathrm{s}$

$\Delta .12 \mathrm{~m} / \mathrm{s}$.

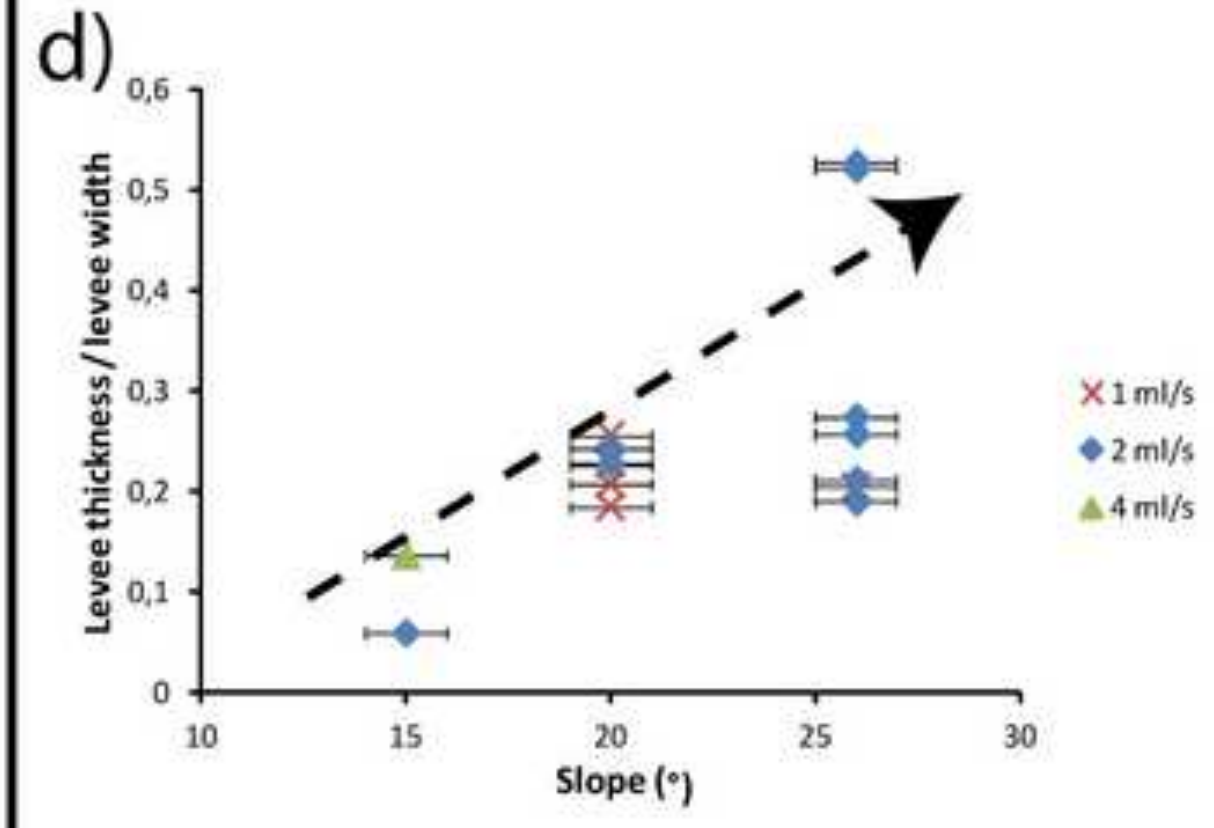



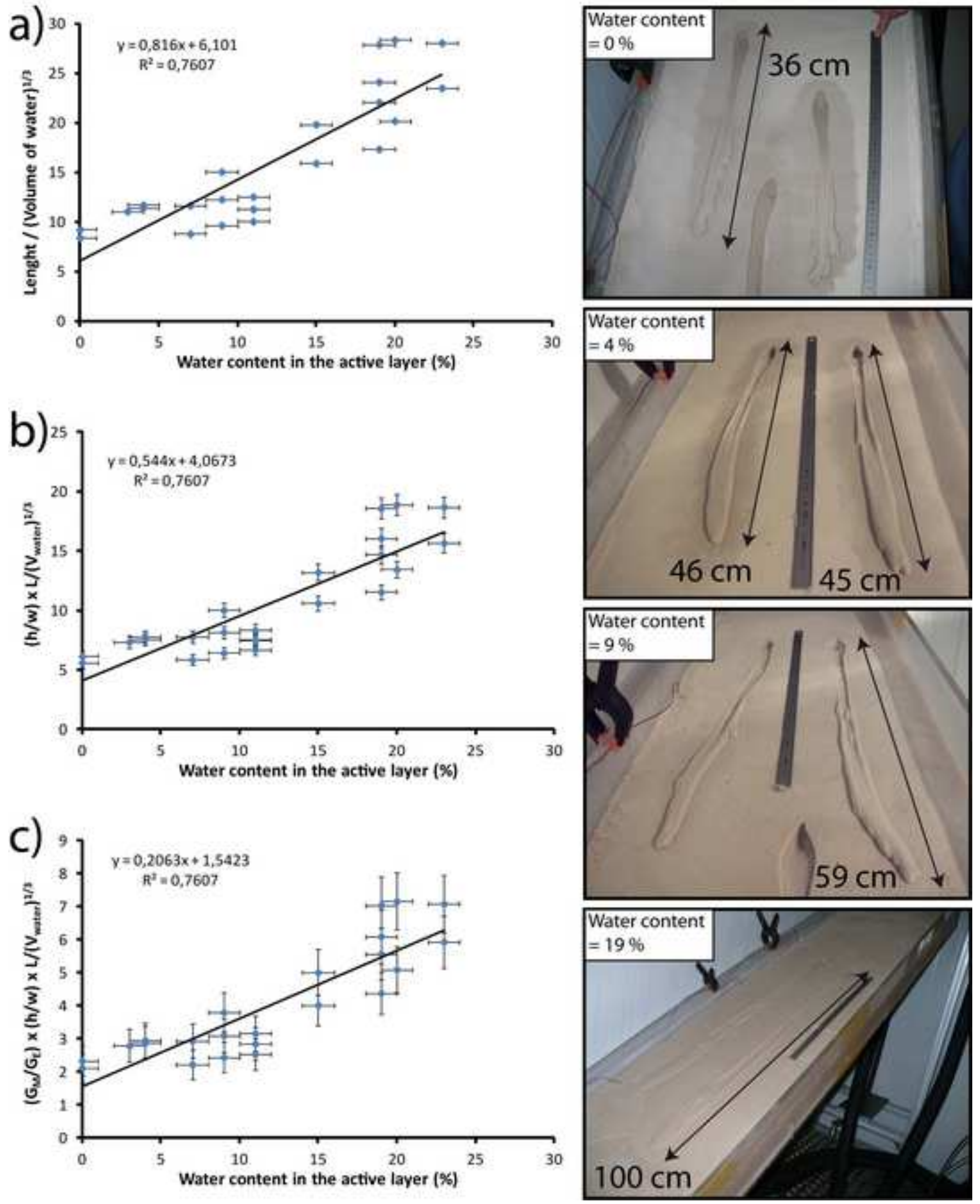
Cold room
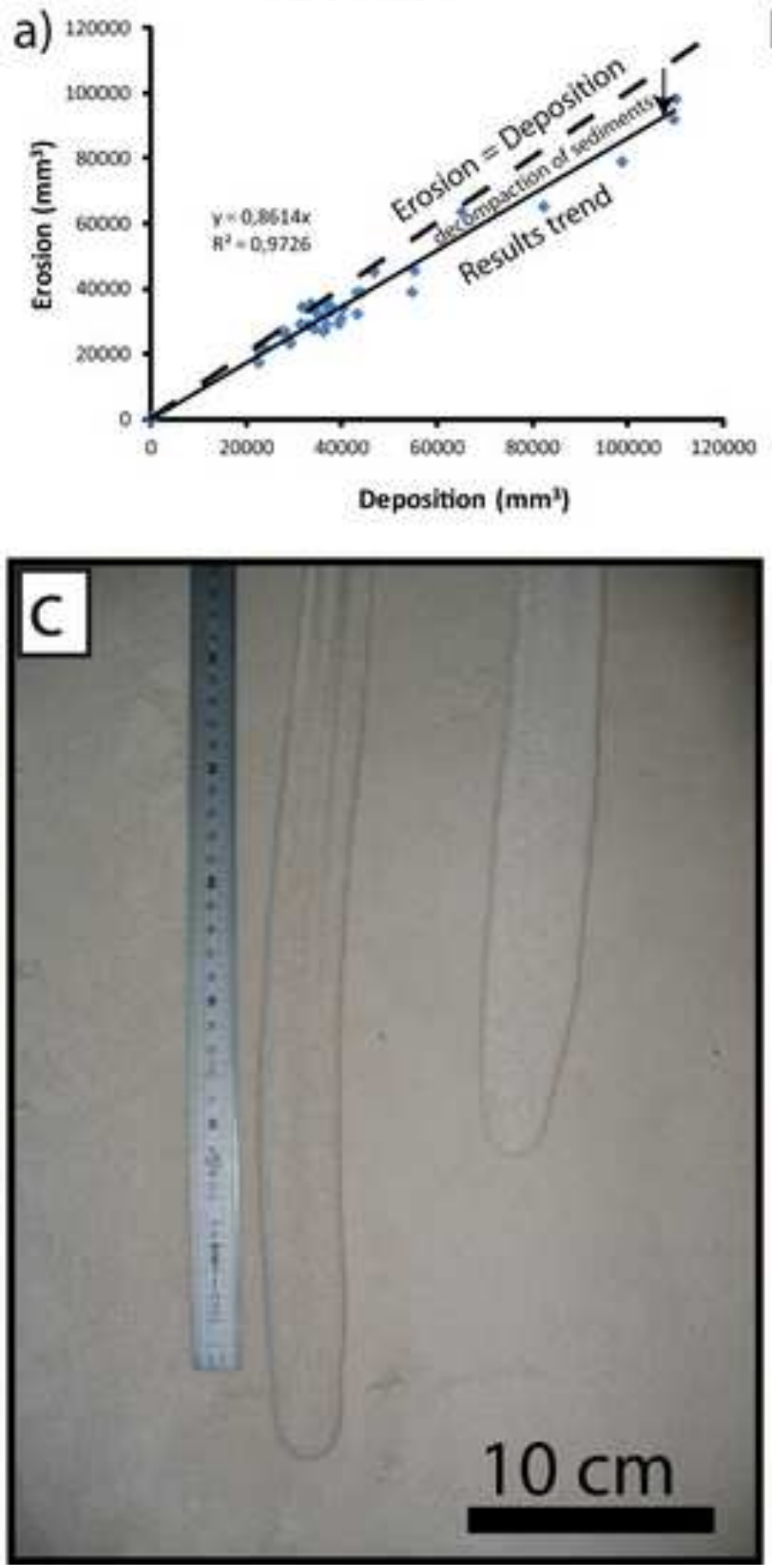

Mars Chamber
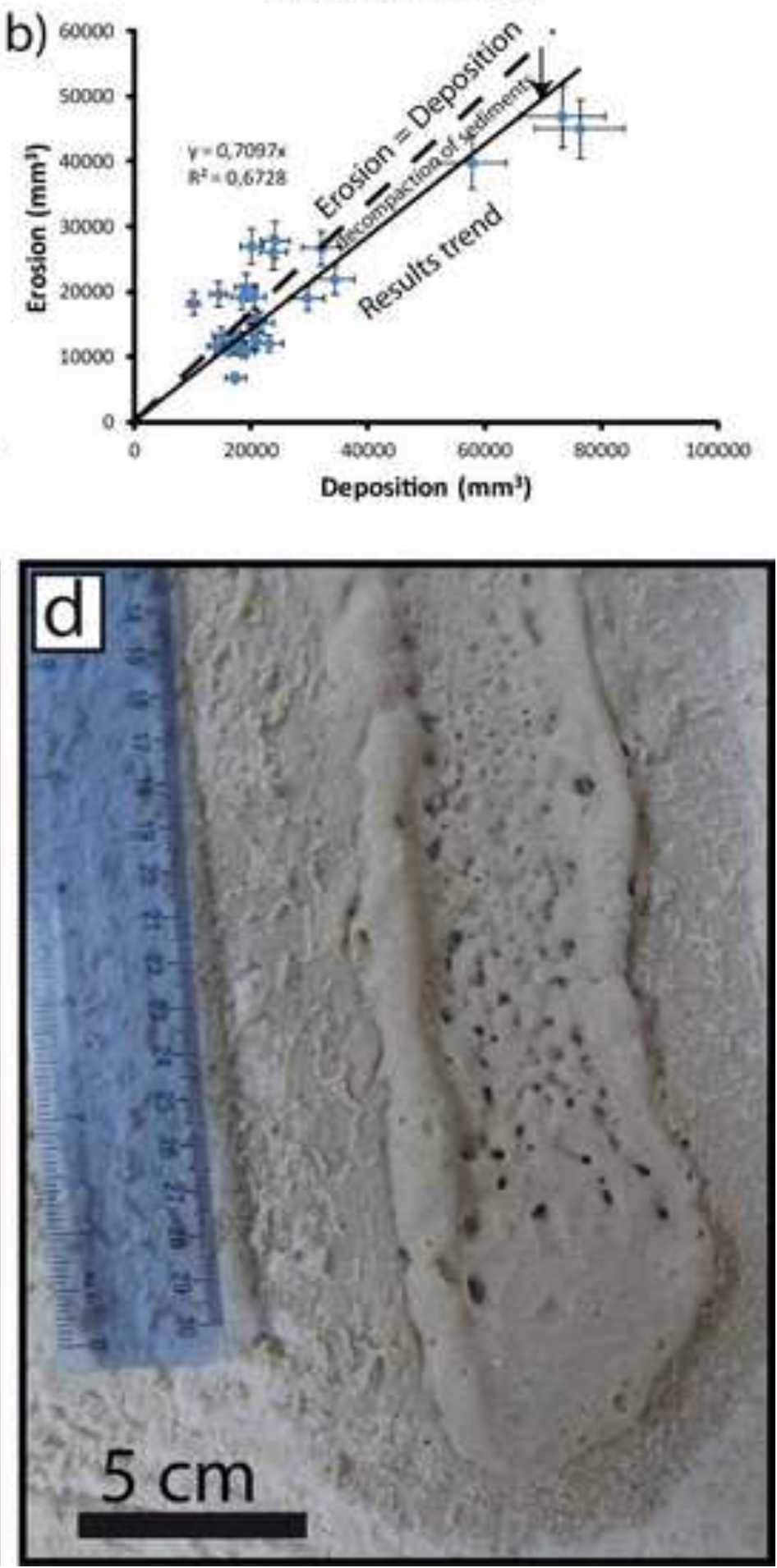
Just after the experiment
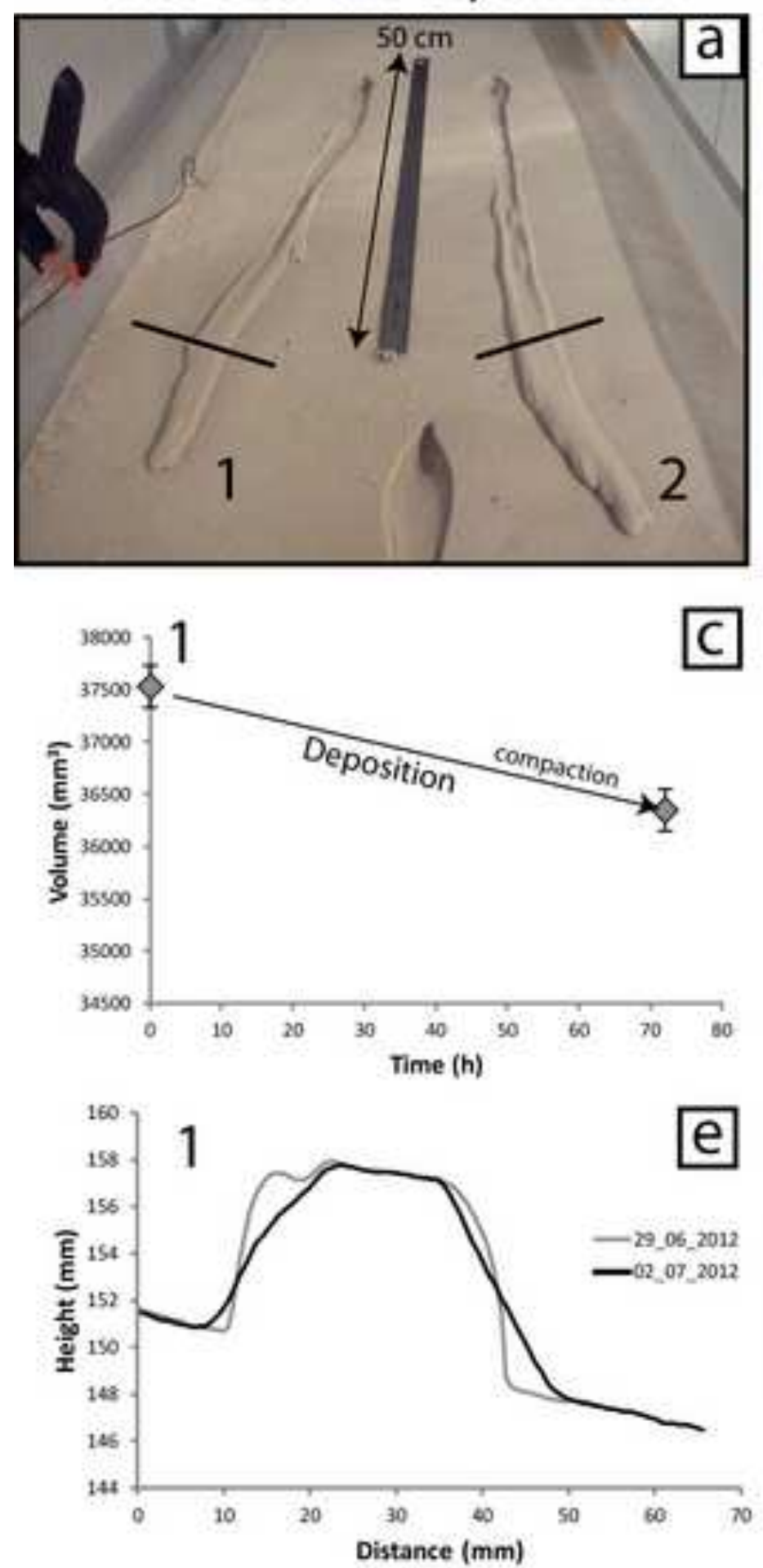

\section{3 days later}
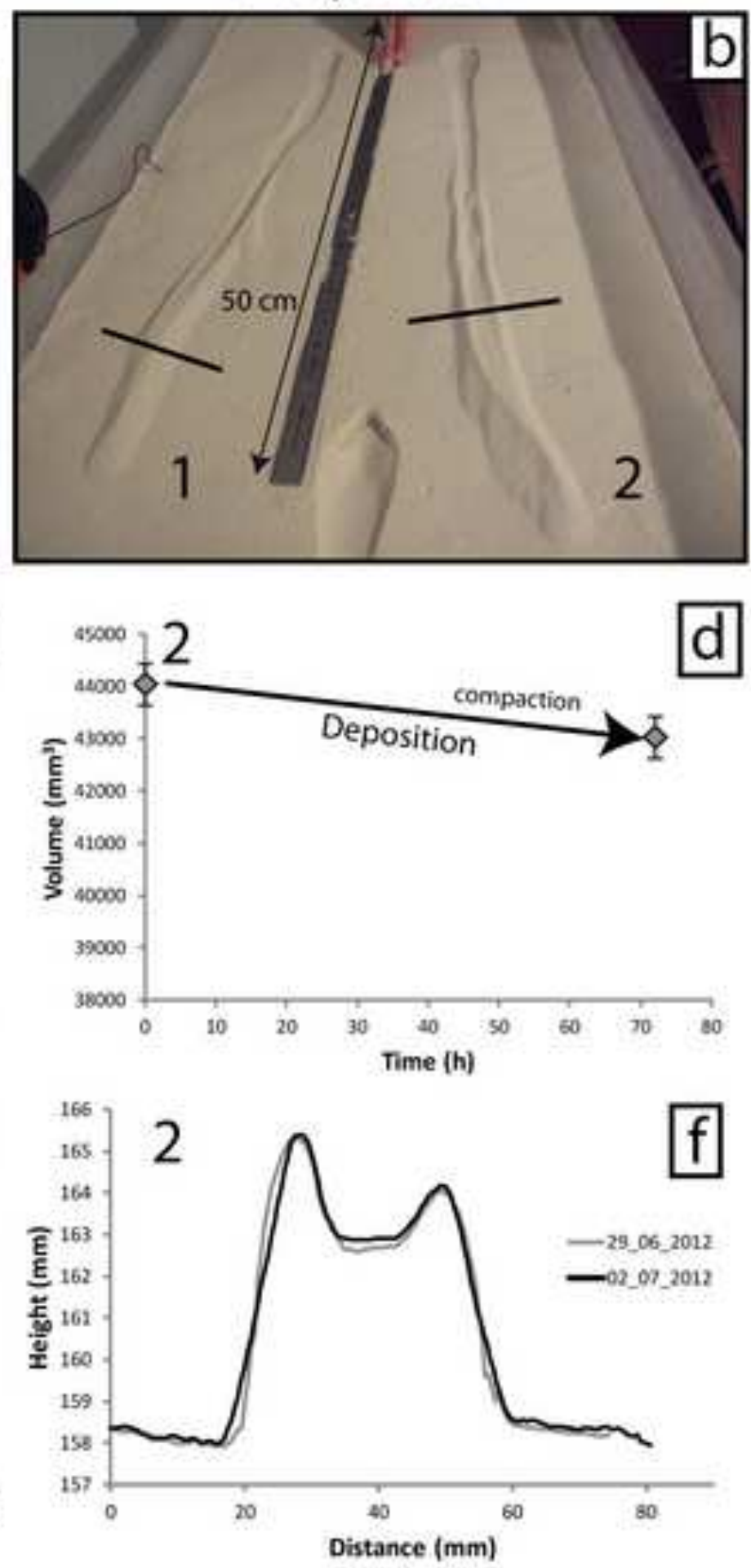


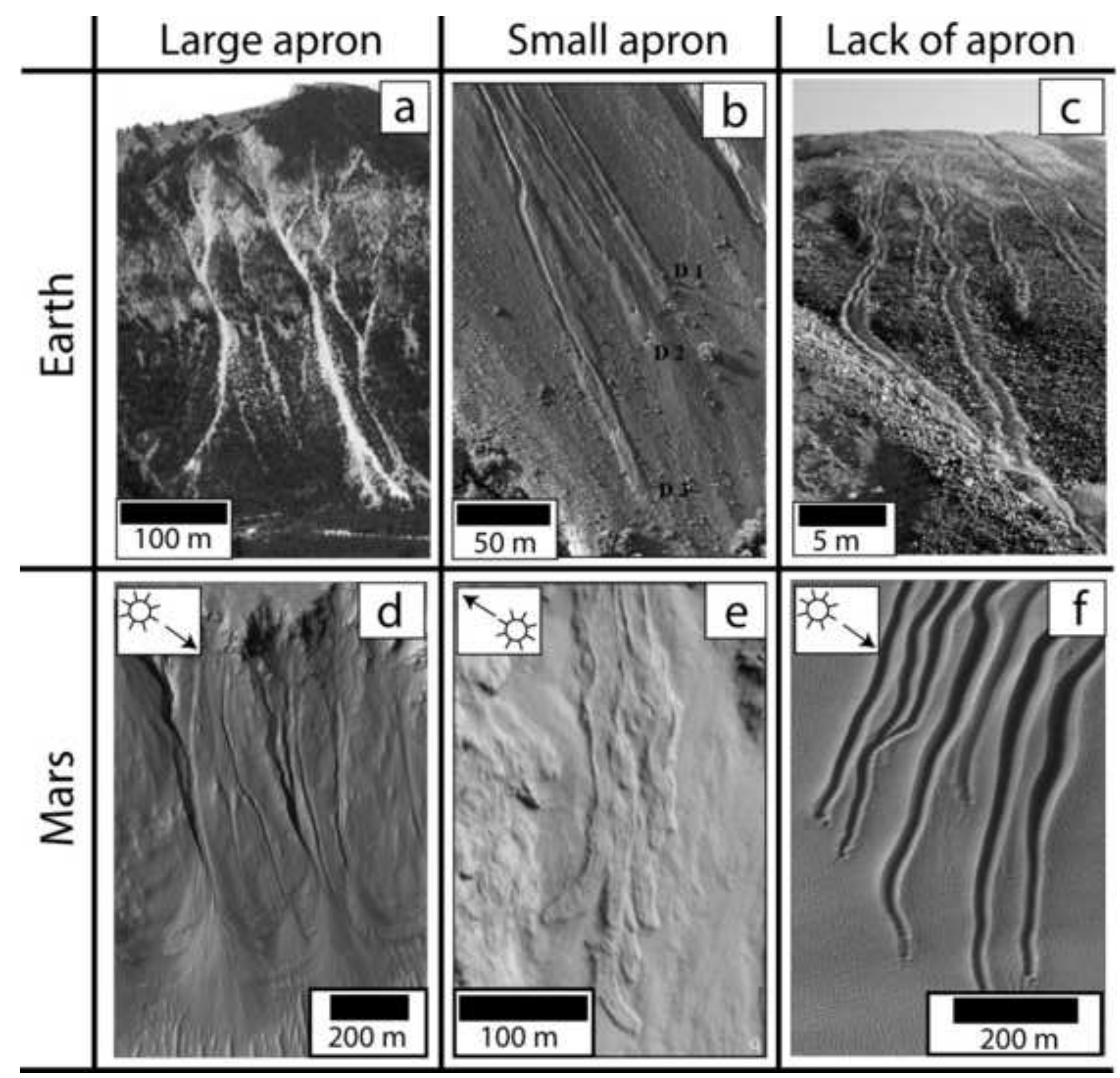


Figure (Greyscale) 2

Click here to download high resolution image
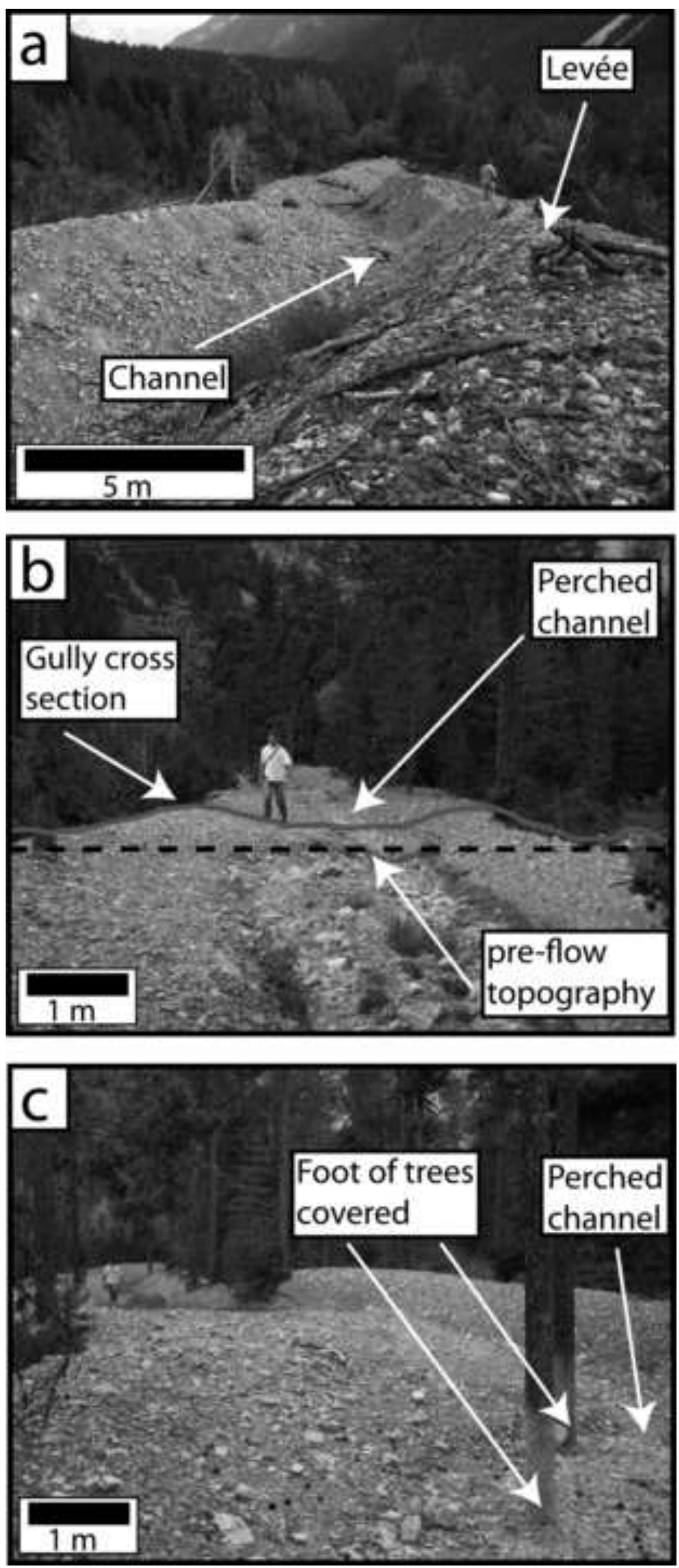
Click here to download high resolution image
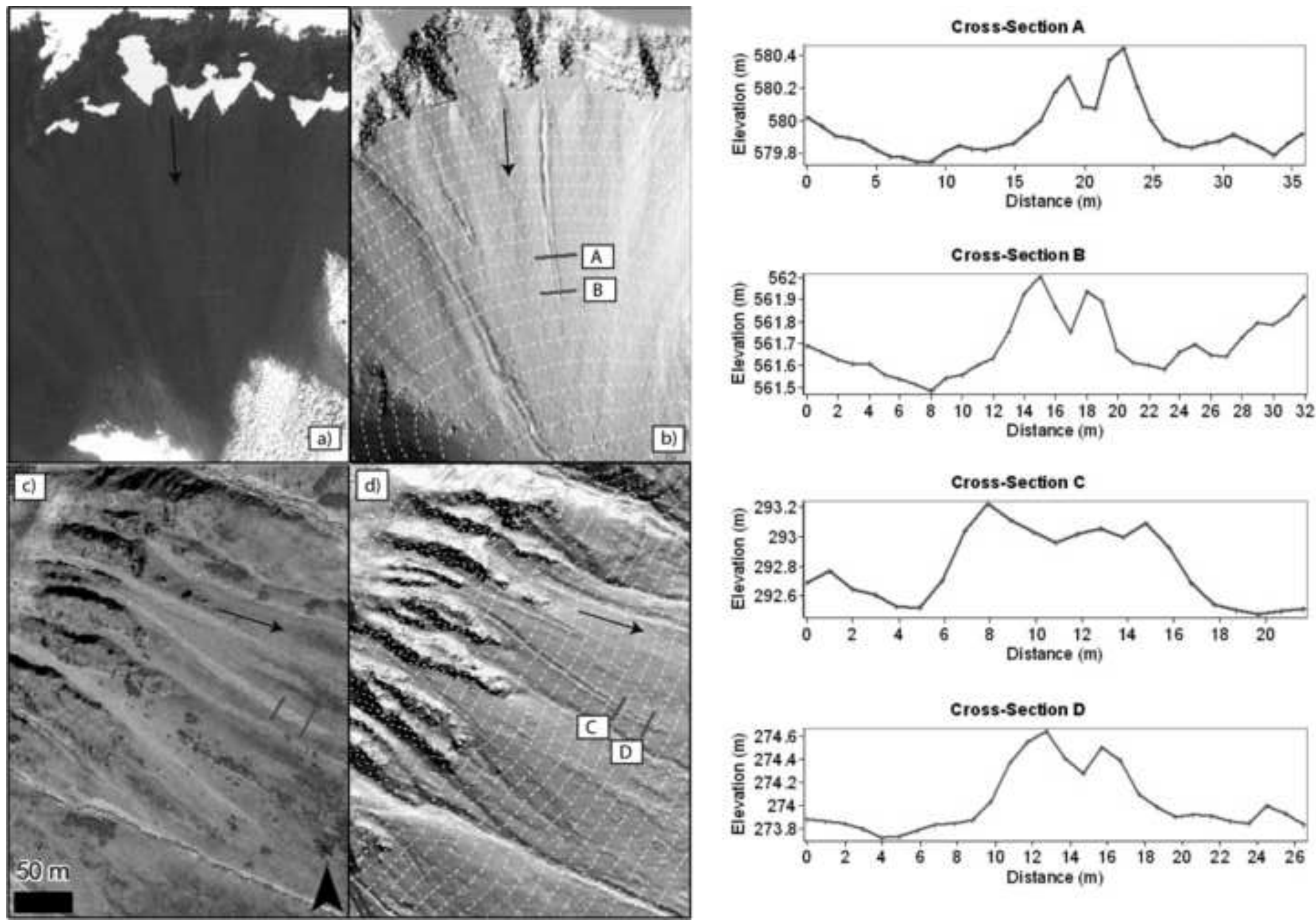

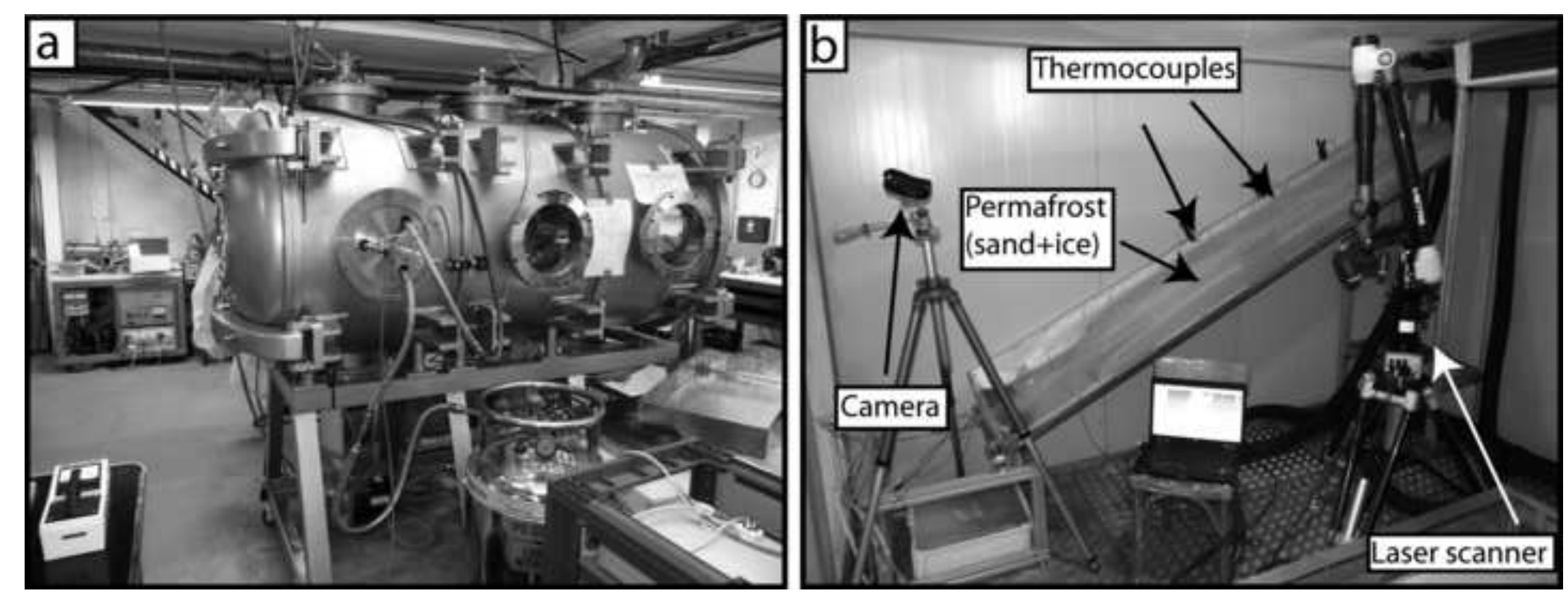

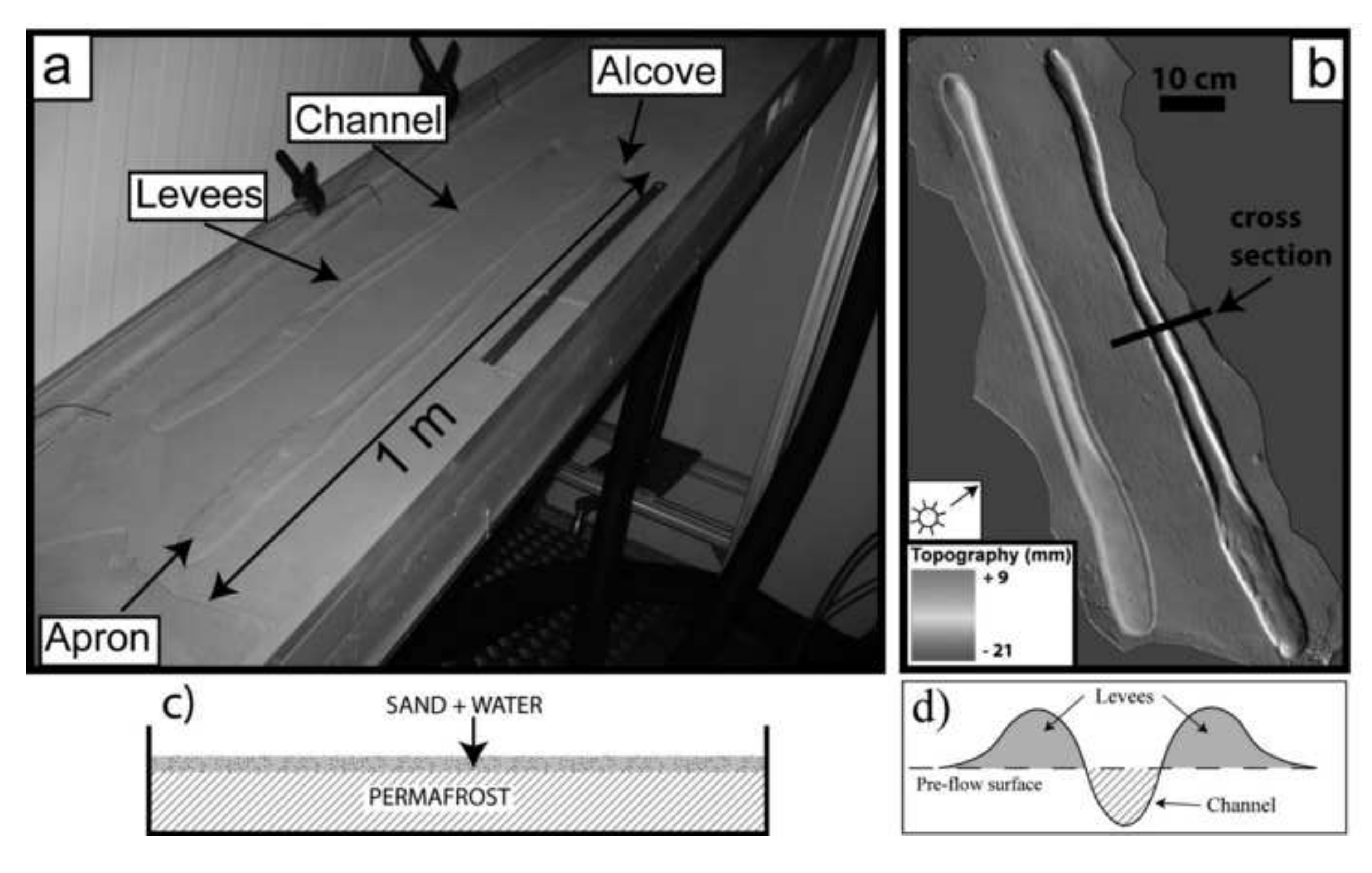





Martian pressure ( $\sim$ mbar)

a)

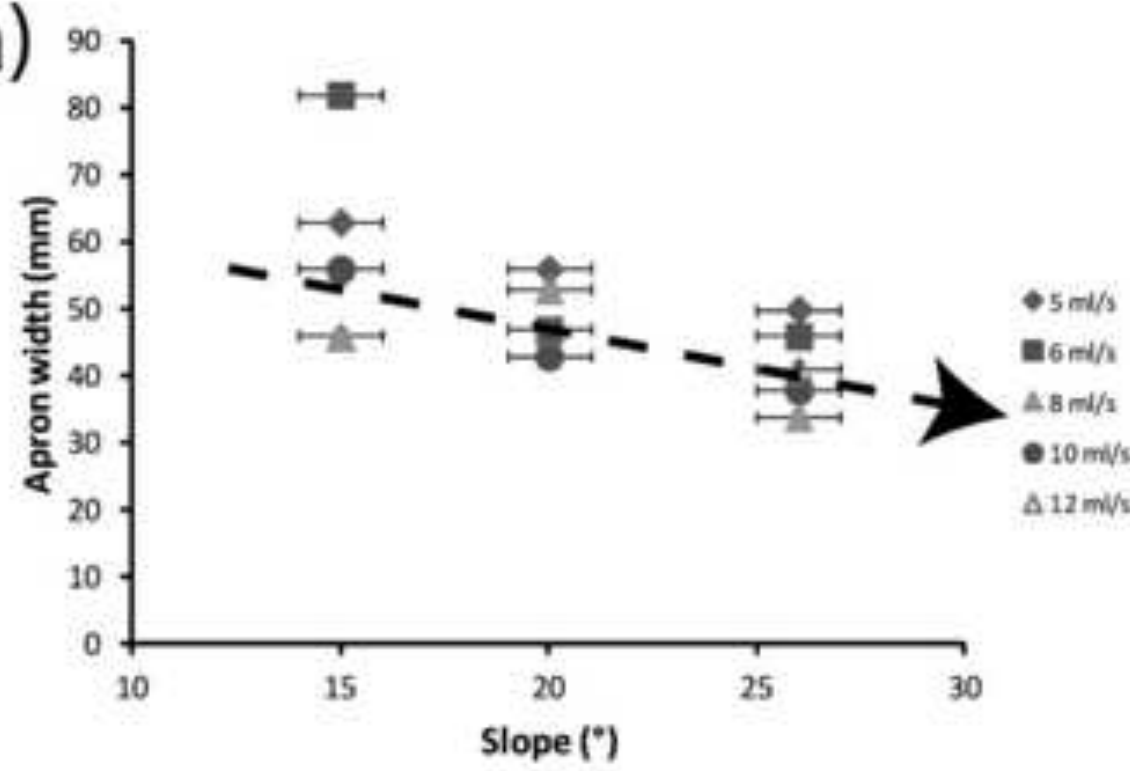

c)

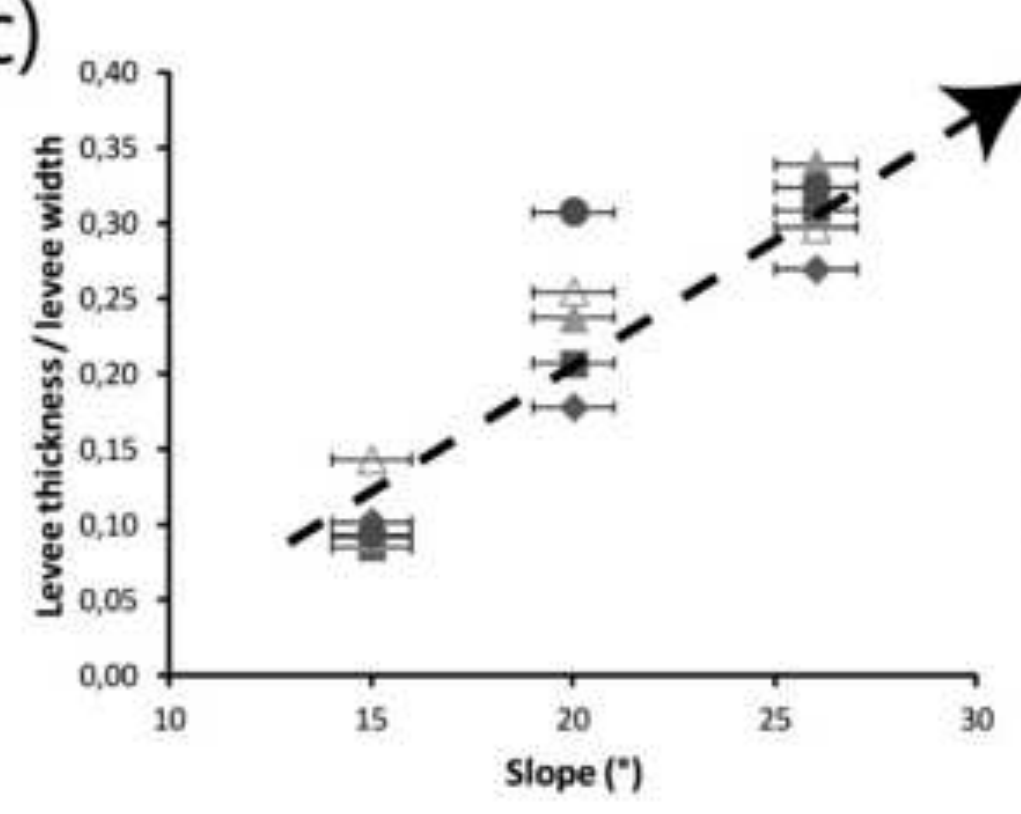

\section{Terrestrial pressure ( $1 \mathrm{bar}$ )}

b)



- $5 \mathrm{mi} / \mathrm{s}$

E $6 \mathrm{ml} / \mathrm{s}$

A $8 \mathrm{ml} / \mathrm{s}$

- $10 \mathrm{~min}$

$\Delta .12 \mathrm{~m} / \mathrm{s}$



|

d)

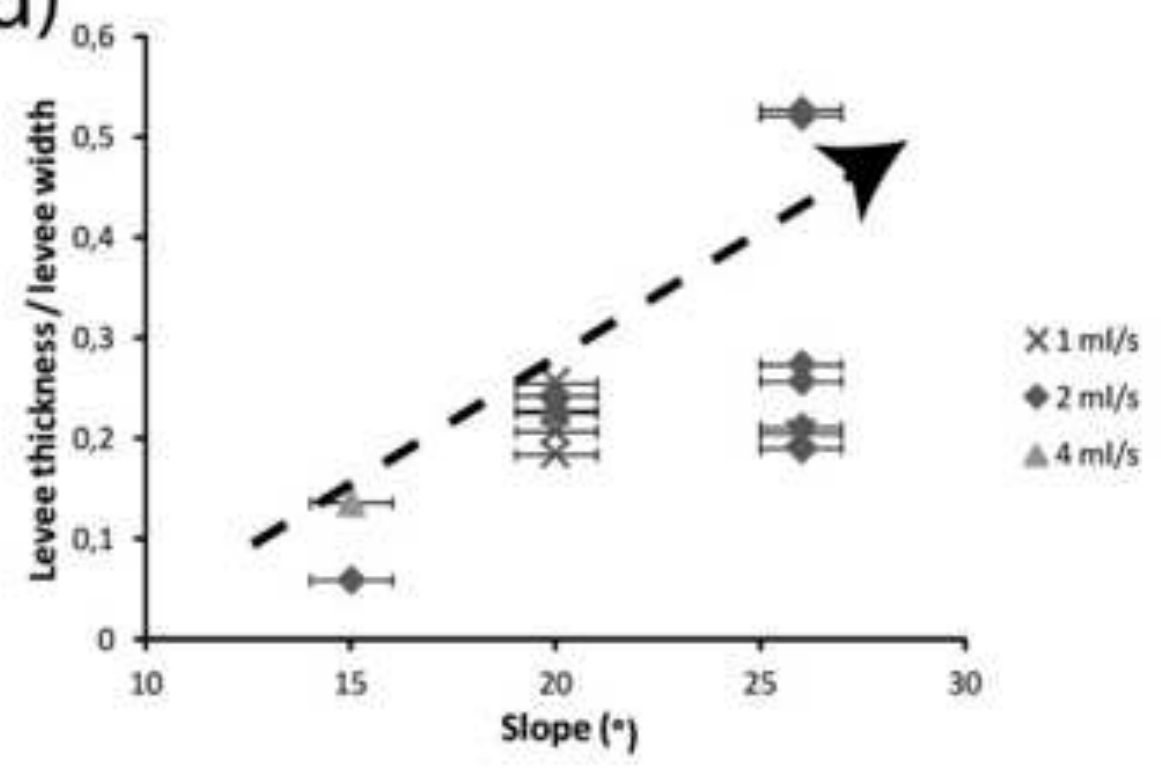



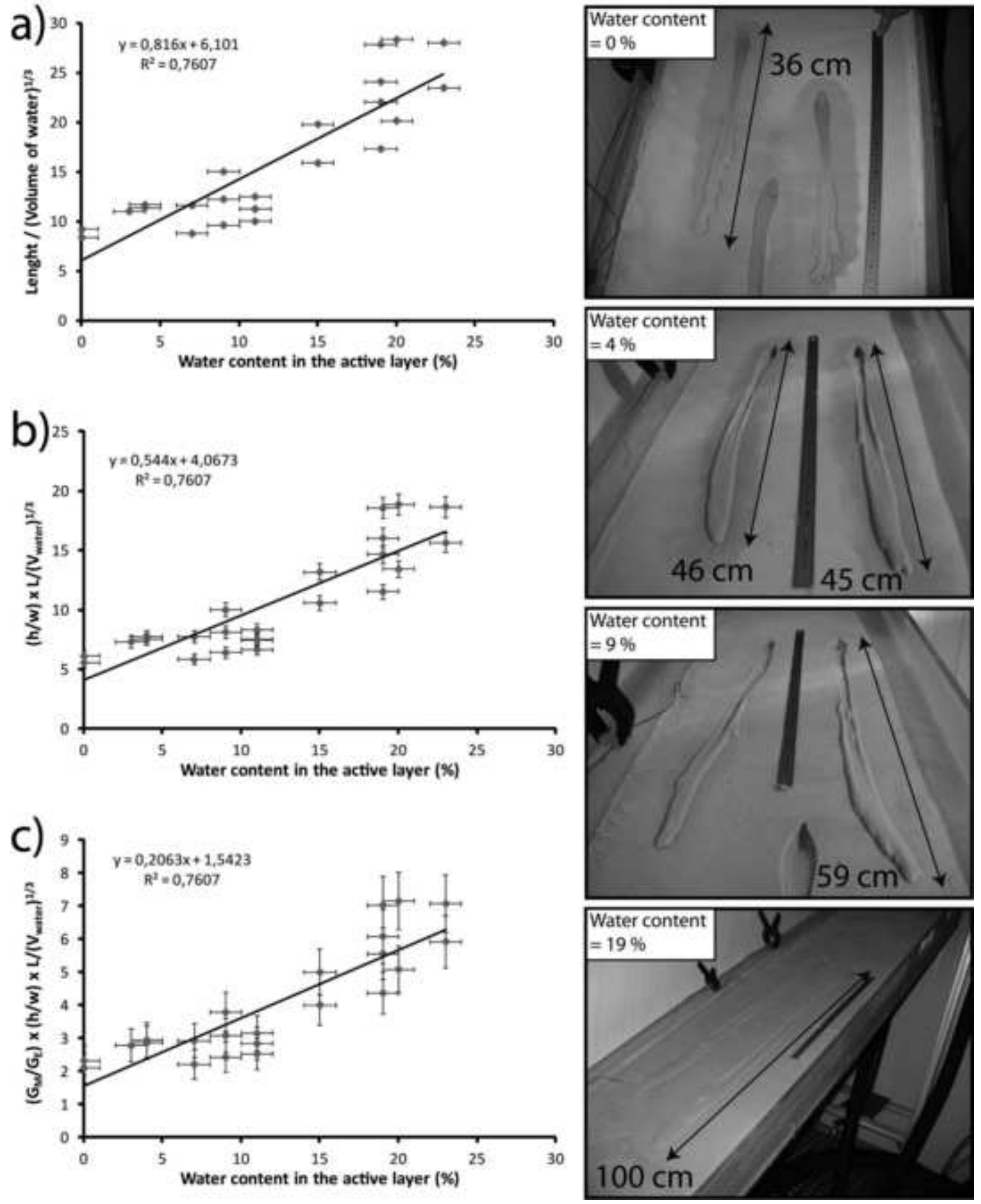
Figure (Greyscale) 9

Click here to download high resolution image
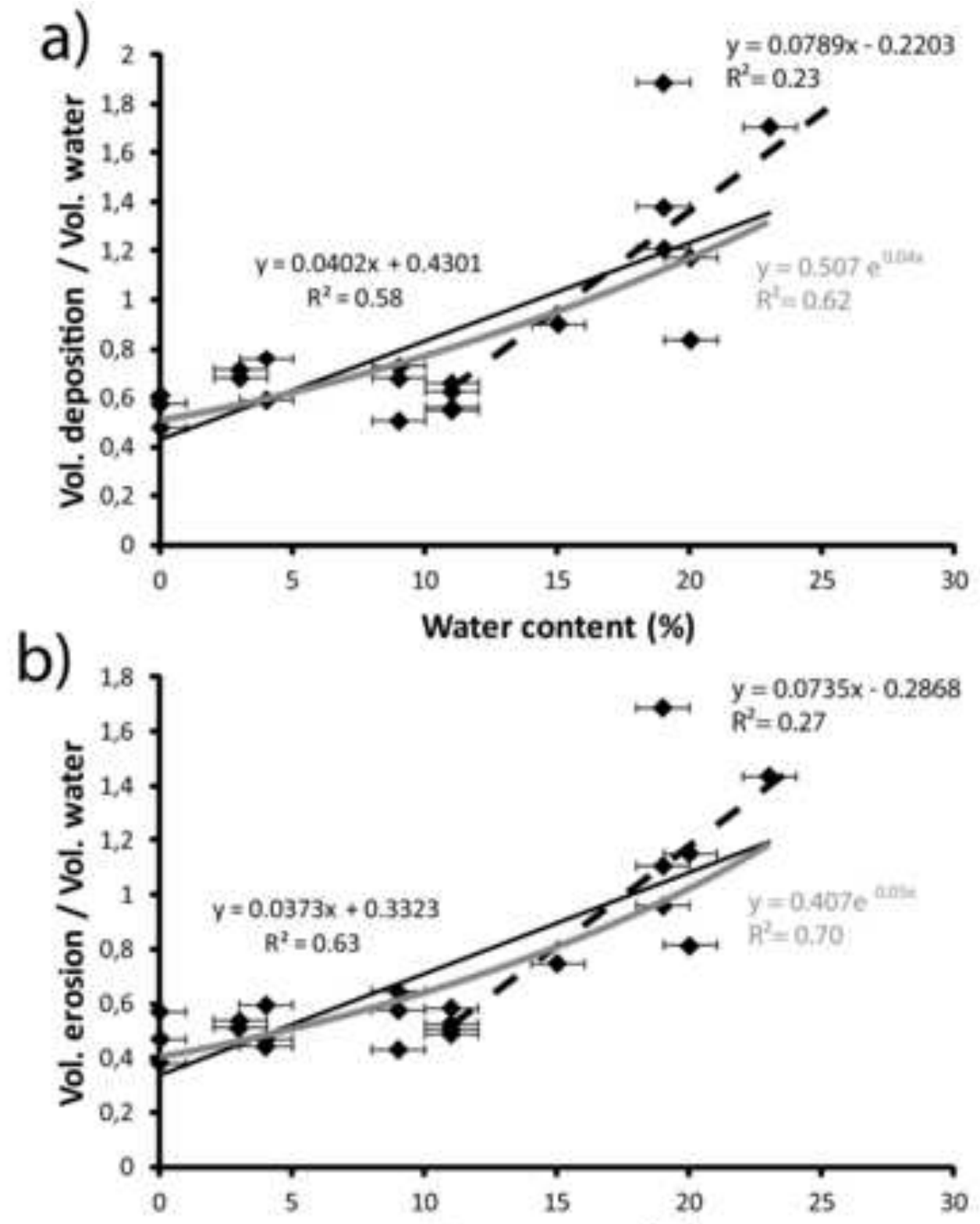

C) Water content (\%)

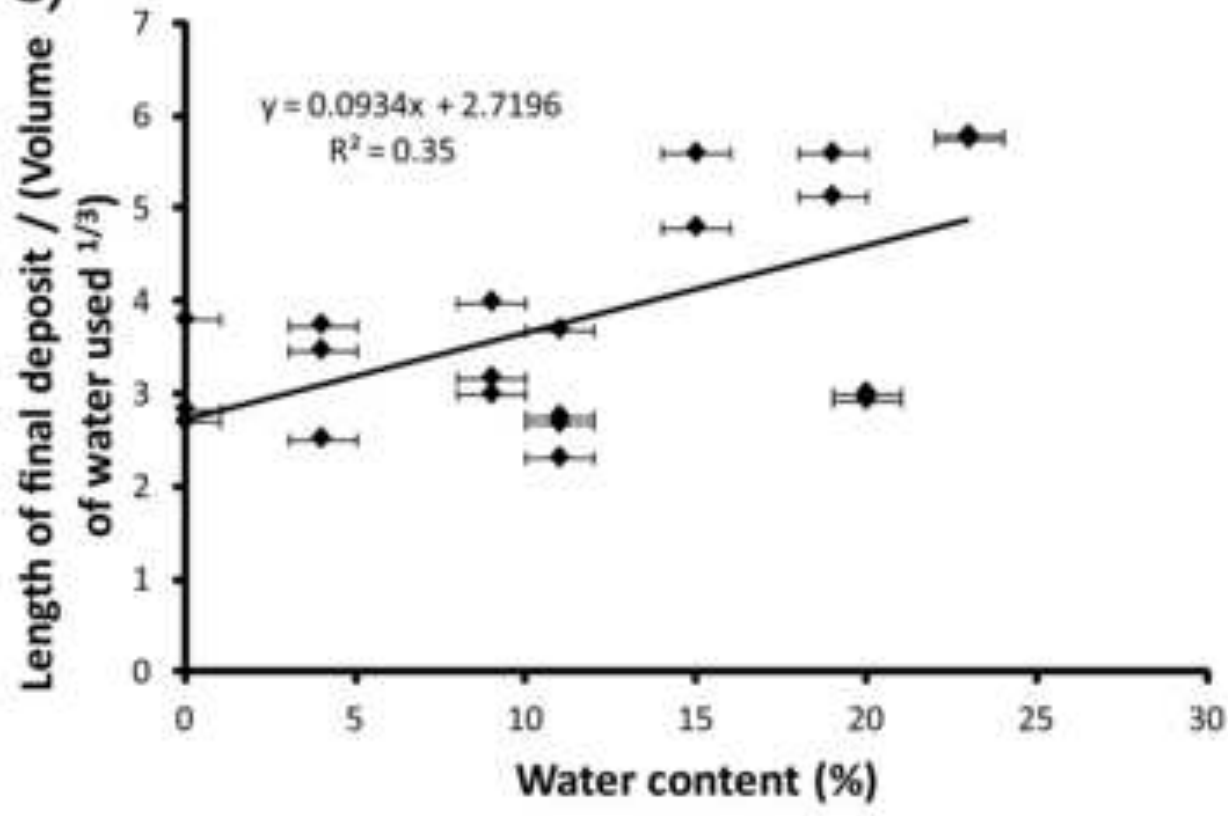


Cold room
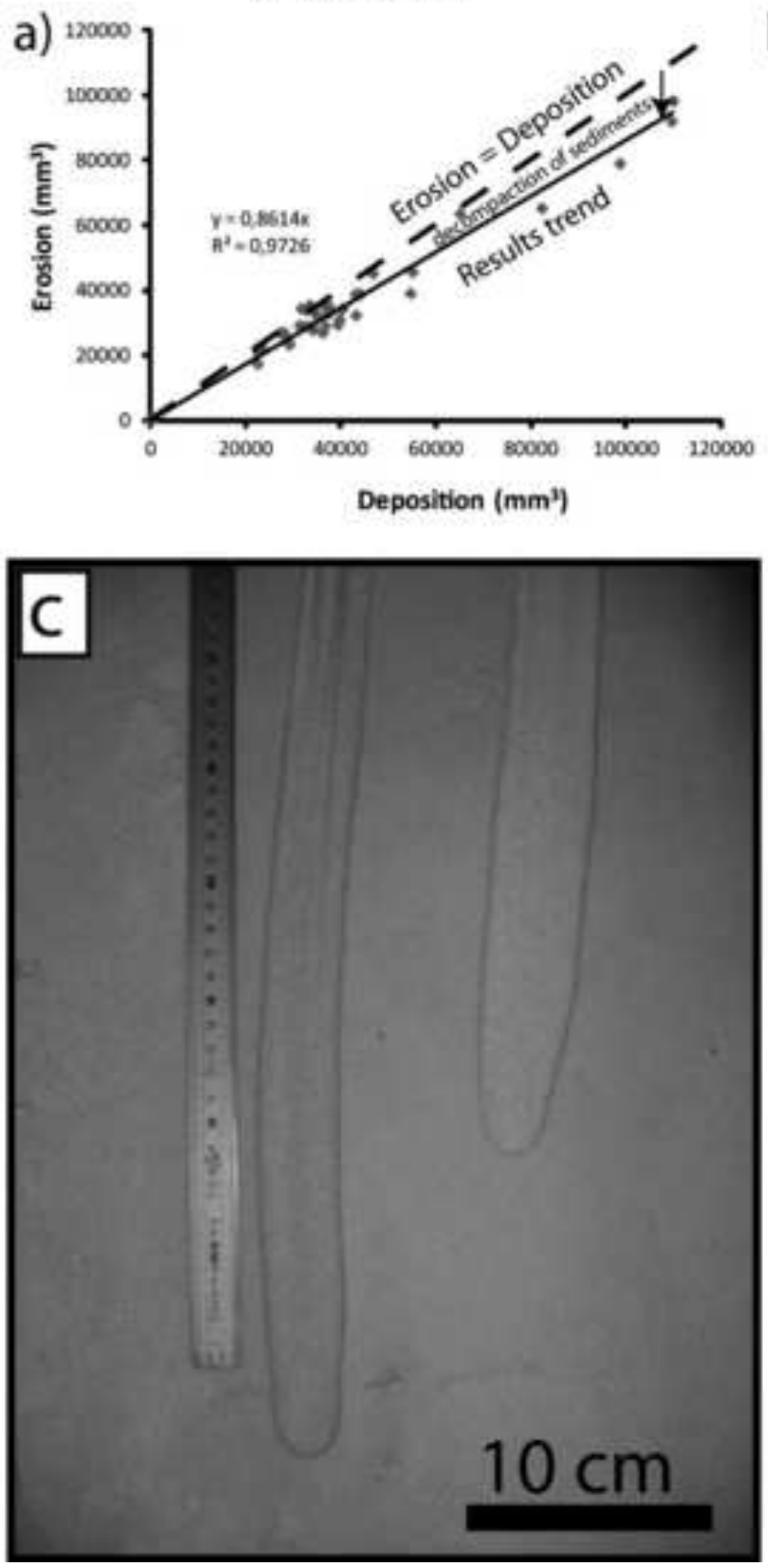

Mars Chamber
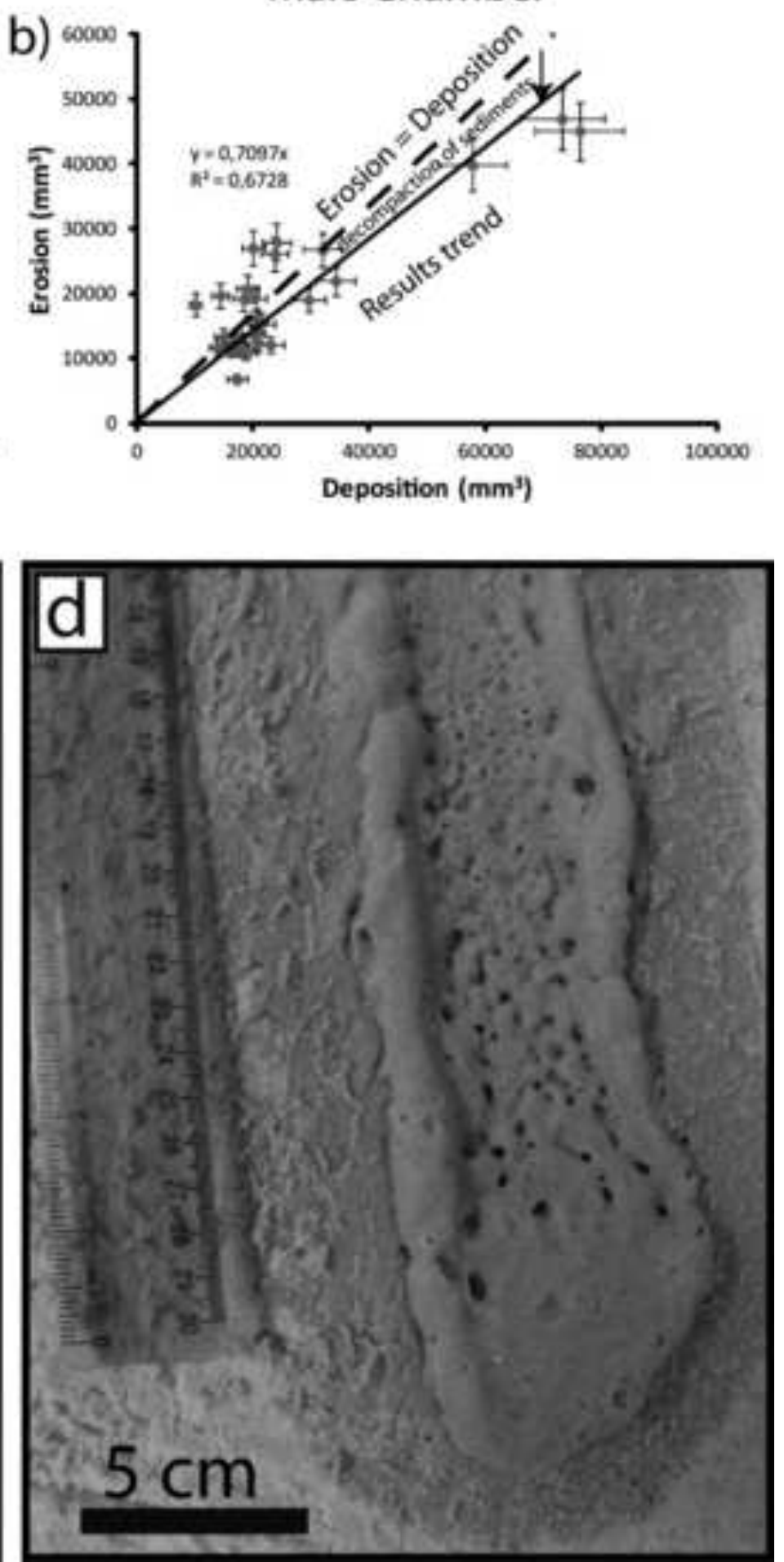
Figure (Greyscale) 11

Click here to download high resolution image

Just after the experiment


\section{3 days later}
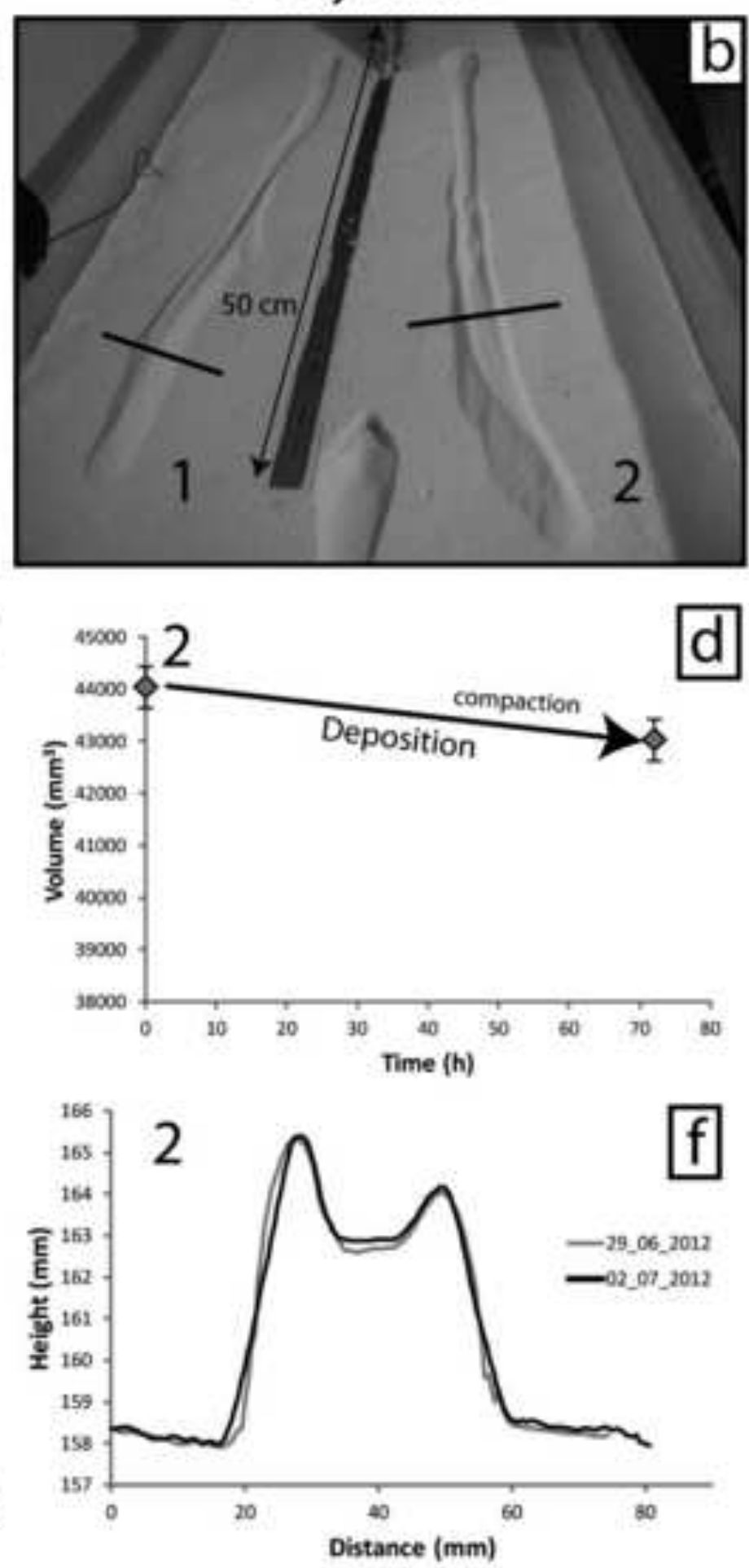